This item was submitted to Loughborough's Research Repository by the author.

Items in Figshare are protected by copyright, with all rights reserved, unless otherwise indicated.

\title{
Summertime temperatures and thermal comfort in UK homes
}

PLEASE CITE THE PUBLISHED VERSION

http://dx.doi.org/10.1080/09613218.2013.757886

\section{PUBLISHER}

(C) Routledge (Taylor \& Francis)

VERSION

AM (Accepted Manuscript)

LICENCE

CC BY-NC-ND 4.0

\section{REPOSITORY RECORD}

Lomas, Kevin J., and Tom Kane. 2019. "Summertime Temperatures and Thermal Comfort in UK Homes". figshare. https://hdl.handle.net/2134/12278. 
This item was submitted to Loughborough's Institutional Repository (https://dspace.lboro.ac.uk/) by the author and is made available under the following Creative Commons Licence conditions.

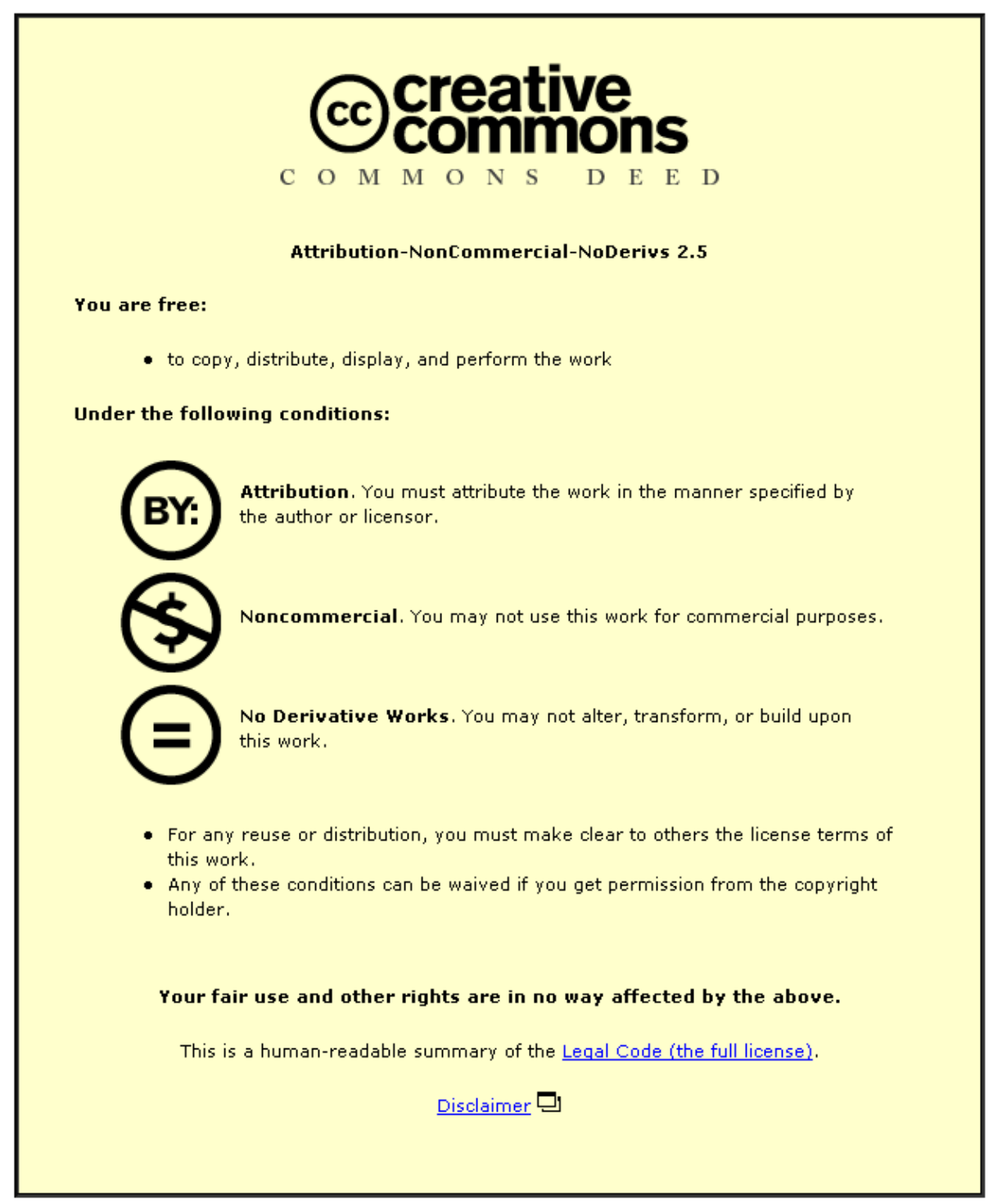

For the full text of this licence, please go to: http://creativecommons.org/licenses/by-nc-nd/2.5/ 


\section{Summertime temperatures and thermal comfort in UK homes}

\section{Lomas $\mathrm{KJ}^{*}$ and Kane T}

School of Civil and Building Engineering, Building Energy Research Group, Loughborough University, Leicestershire, LE11 3TU, UK.

k.j.lomas@lboro.ac.uk, t.kane@lboro.ac.uk

*Corresponding author.

Total words $-10,900$

\section{Abstract \\ Abstract [213 words]}

Internal summertime temperatures measured in 268 homes in the UK city of Leicester are reported. The hourly data was collected from living rooms and bedrooms during the summer of 2009, which was generally cool but with a short hot spell. Some household interviews were conducted. The sample of homes is statistically representative of the socio-technical characteristics of the city's housing stock. The data provides insight into the influence of house construction, energy system usage and occupant characteristics on the incidence of elevated temperatures and thermal discomfort.

The warmest homes were amongst the $13 \%$ that were heated. Significantly more of these were occupied by those over 70 who are particularly vulnerable to high temperatures. The national heatwave plan might usefully caution against summertime heating.

Temperatures in the 230 free-running homes were analysed using both static criteria and criteria associated with the BSEN15251 adaptive thermal comfort model. These indicated that that flats tended to be significantly warmer than other house types. Solid wall homes and detached houses tended to be significantly cooler.

It is argued that adaptive criteria provide a valuable and credible framework for assessing internal temperatures in free-running UK homes. However, the temperatures in the Leicester homes were much lower than anticipated by the BSEN15251 model. Numerous possible reasons for this discrepancy are discussed.

Key words: Comfort, UK houses, temperature measurement, summer.

\section{Introduction}

Summertime temperatures in homes are of increasing concern, even in the relatively mild climate of the UK because very high indoor temperatures can be life threatening and are likely to occur more often as global temperatures rise. Whilst elevated temperatures can be overcome with air conditioning, this would simply increase electricity use and be, for the UK at least, a new source of greenhouse gas emissions. Conversely, many UK householders switch their heating systems off in summer. Thus during cooler weather, internal temperatures can be low, which, because the fabric of the home will be cool, creates a buffer against hotter spells of weather. There is therefore an interest in understanding what summertime temperatures are in UK homes and how these might be influenced by house type, construction and occupant characteristics.

Heat stress in homes is of particular concern. The European heat wave of 2003, which has been particularly closely studied, was most intense in the UK in August. It is estimated to have caused an additional 2045 deaths in the UK (ONS, 2003) with as many as 70,000 excess deaths between June and September, across Europe as a whole (WHO, 2007). During the 2003 heat wave, Wright et al (2005) measured the internal temperatures in five London flats 
and in four homes around Manchester. The heat wave lasted 9 days in Manchester and 12 days in London. In Manchester, the maximum daily mean temperature was $25.4^{\circ} \mathrm{C}$ with an absolute peak of $32.1^{\circ} \mathrm{C}$; corresponding values for London were $29.3^{\circ} \mathrm{C}^{1}$ and $37.4^{\circ} \mathrm{C}$. In both locations, the daily average external temperature was always above $20^{\circ} \mathrm{C}$, except for one day in Manchester. In Manchester the living room of one home reached $30^{\circ} \mathrm{C}$ and one of its bedrooms $36.0^{\circ} \mathrm{C}$, and a London flat reached $37.9^{\circ} \mathrm{C}$, which is dangerously high given the imperative to maintain our core temperature very close to $37^{\circ} \mathrm{C}$.

Whilst the summer of 2003 was very unusual for our current climate, projections indicate that similar extreme weather events will take place every two or three years by the 2050s (Mayor of London, 2008) and by the 2080s, such temperatures would be considered unusually cool (Eames et al., 2011). There is therefore interest in knowing the extent to which UK homes should be adapted to withstand higher summertime temperatures and whether adaptation is necessary for all house types and in all geographical areas. One obvious adaptive measure is to install air-conditioning, but this would simply increase summertime energy demands and hinder progress towards a low-carbon future.

Using mortality data for the Greater London region for 1976 to 1996, Hajat et al (2002) showed that an average daily external temperature over $19^{\circ} \mathrm{C}$ seems to lead to an increase in heat related deaths. The rate of increased deaths was related to the degree to which the three day moving average external air temperature exceeded the $97^{\text {th }}$ centile value ${ }^{2}$. The use of a moving average temperature enables hot spells rather than isolated hot days to be identified. It also corresponds rather well to the way that indoor temperatures change with external conditions; they tend to be influenced by the external temperature over the recent past rather than the instantaneous external temperature. The use of a locally defined threshold, i.e. the $97^{\text {th }}$ centile value, suggests that deaths due to a heat wave will be fewer in areas that are generally warm, like the south east of England, than if a heat wave of the same intensity and duration hit a region that is generally cooler, such as the more northerly areas of England. Modern, adaptive thermal comfort standards published since the Hajat study, whilst concerned with general comfort rather than heat stress, are based around a moving average external temperature and have thresholds that increase as external temperature increases. They are considered herein as a method for identifying householders at risk of exposure to high temperatures.

The UK National Health Service has produced a heat wave plan contains advice on coping with extreme weather events (NHS, 2011). Using data for the hot summer of 2006, it notes that external temperatures over $25^{\circ} \mathrm{C}$ led to increased mortality. The greatest temperaturerelated mortality occurred in the West Midlands, where there were 160 excess deaths between $16^{\text {th }}$ and $28^{\text {th }}$ July (an increase of $10 \%$ above the base level) ${ }^{3}$. Most at risk are: the elderly, especially, women over 75; those living alone or the socially isolated; those with chronic or severe illnesses; individuals that cannot take adaptive measures to keep cool, e.g. the bedbound, those with Alzheimer's disease, or babies and the very young; and those living in urban areas and in south-facing top floor flats. The heatwave plan causes warnings of possible heatwaves to be issued in a region if there is a $60 \%$ or greater risk that forecasted external temperatures will exceed listed threshold values for 2 or more days. For most of the country, including the East Midlands, which is where the homes studied in this paper were located, the listed thresholds are $30^{\circ} \mathrm{C}$ in the day and $15^{\circ} \mathrm{C}$ at night. The heatwave plan

\footnotetext{
${ }^{1}$ In Leicester, the temperatures in August 2003 reached a peak of $37.0^{\circ} \mathrm{C}$ (on August $9^{\text {th }}$ ) with a maximum daily mean of $25.2^{\circ} \mathrm{C}$ (on August $6^{\text {th }}$ ) and a maximum $\mathrm{T}_{\mathrm{rm}}$ value of $21.4^{\circ} \mathrm{C}$ (on August $11^{\text {th }}$ ).

${ }^{2}$ In London the $97^{\text {th }}$ centile value of the three day moving average temperature from $1976-96$ was $21.5^{\circ} \mathrm{C}$.

${ }^{3}$ The South East and Yorkshire and Humberside experienced the second highest temperature-related death rates with 110 excess deaths (4\% above base level) and 100 deaths (6\% above base level), respectively.
} 
provides an example of how internal temperatures can be reduced by insulating a home. Taking cold drinks, checking temperatures, opening windows at night and moving to a cooler room are all cited as measures to reduce overheating risk; turning off heating systems is not explicitly stated ${ }^{4}$.

Modelling studies, for example by Hacker et al. (2008), have shown that thermal mass and controlled ventilation can much improve summertime thermal comfort. In a thermally massive home in the London region, bedroom temperatures were predicted to become excessive in the 2080s, but in a lightweight home overheating was predicted to set in as early as the 2020s. Similarly, Peacock et al. (2010) have shown that solid masonry wall homes are more comfortable in summer than thermally lightweight dwellings, which, in the London region, become uncomfortably hot by the 2030s. The ability to maintain bedrooms at a comfortable temperature was noted as being of paramount importance in understanding overheating risk. Mavrogianni et al. (2012) studied the impact of energy efficient refurbishment on the internal temperatures of homes in London. They noted that retaining exposed thermal mass and the ability to ventilate effectively would enable mean and peak internal temperatures to be controlled up to the 2050s, but internal insulation that masked thermal mass led to increased internal temperatures.

Although modelling studies are extremely useful, it is difficult to capture credibly the full variability of occupant behaviour and house construction, geometry and ventilation potential. In contrast, measurement can capture such diversity and, if the study is sufficiently detailed and large enough, also relationships between those that are vulnerable to extreme temperatures, such as the elderly, sick and the very young, and the homes in which they live. There are, however, few large UK studies of summertime temperatures in homes; most largescale studies have focused on winter temperatures ${ }^{5}$. The energy follow-up survey commissioned by the UK Department of Energy and Climate Change in 2010, to supplement the data from the English housing survey, could help fill this gap.

This paper also contributes to our knowledge of actual summertime temperatures in UK homes. To the authors' knowledge it is the first large-scale and detailed study that has been reported. It presents an analysis of the internal temperatures recorded in 268 homes in the UK city of Leicester during the summer of 2009. The monitoring period contained a short period of hot weather followed by two cool months. The spur to this paper was an analysis of elevated temperatures, which was assessed using established 'static' overheating criteria. Perhaps the more interesting results originate from the analysis of the thermal comfort conditions during the cool weather, which was assessed using an adaptive model of thermal comfort. The paper identifies any significant relationships between thermal comfort and elevated temperatures and house type and age, construction, tenure and occupancy.

\section{Household survey and temperature measurements}

Leicester was the case study city chosen by the $4 \mathrm{M}$ project consortium that was concerned with the determination of city carbon footprints (Lomas et al., 2006). Leicester is geographically central in England and has a clearly identifiable boundary with the surrounding rural area (Fig. 1). With a resident population of 280,000 in 2007, living in over

\footnotetext{
${ }^{4}$ Hidden in a figure is advice to 'reduce internal energy and heat'.

${ }^{5}$ This is not surprising as in the UK wintertime space heating energy demands are a major source of greenhouse gas emissions and under heating of homes is a significant health risk. Such studies include, for example, 1600 low income households (Oreszczyn et al., 2006), 427 homes in the CaRB study (Shipworth et al., 2009), 14 lowenergy homes monitored in Milton Keynes (Summerfield et al., 2007) and 25 households in Northern Ireland (Yohanis et al., 2010). The most extensive field survey (Hunt \& Gidman, 1982) measured spot temperatures in each room of 100 homes in February and March 1978.
} 
111,000 homes (ONS, 2010), Leicester is the UK's $15^{\text {th }}$ largest city and has households that cover a wide range of socio-economic categories, from affluent to the most disadvantaged.

The most frequent housing types are semi-detached (37\% of the city's housing stock) and terraces (35\%), which proliferate towards the city centre along with flats (17\%) (Table 1). The detached houses are found primarily in the suburbs (10\%) (ONS, 2010). Over the years, many homes have been made more energy efficient using insulation and modern boilers and controls.

One aim of 4M was to measure domestic energy use, travel behaviour and garden management practices. To do this, a face-to-face computerised questionnaire was administered at 575 homes (i.e. $0.5 \%$ of Leicester homes). These were randomly selected after stratifying by percentage of detached homes and percentage with no dependent children (Fig. 1), which is important here as the thermal comfort of the elderly is of interest ${ }^{6}$. The questionnaire was devised by the $4 \mathrm{M}$ team and conducted on their behalf by the National Centre for Social Research (NATCEN) between $17^{\text {th }}$ March and $18^{\text {th }}$ June 2009. Relevant to this work, the survey captured the house type ${ }^{7}$, the number of occupants, the age of the oldest occupant, the age of the house, whether the loft or walls were insulated or not, and the mode of tenure. The responses of the interviewees were recorded directly onto a laptop and then downloaded, cleaned and organised in the $4 \mathrm{M}$ database. The $4 \mathrm{M}$ Living in Leicester (LiL) survey provides a consistent and comprehensive data set about households, their home energy demand, travel behaviours and garden management practices. It is the first such data set collected in the UK and has been exploited for a number of purposes.

As part of the LiL survey, Hobo pendant-type temperature sensors (Fig. 2) were used to record internal temperatures over an eight-month period beginning on $1^{\text {st }}$ July 2009 . The temperature measured approximates to air temperature, but, as the sensors were unshielded, they will also record a radiant component. The primary purpose was to capture the internal temperatures during the winter heating season (Kane et al., 2011). The sensors take a spot measurement of temperature on each hour point. They were calibrated by the manufacturer and found to be accurate to $\pm 0.4^{\circ} \mathrm{C}$ (Tempcon Instrumentation Ltd, 2010).

NatCen interviewers asked the occupants to place the sensors in the living room and main bedroom; 94 households did not, however, want to take the sensors (Fig. 3). Guidance was provided, which stated that they should be placed away from heat sources and not in direct sunlight. At the end of the monitoring period, households were asked to return the sensors in pre-paid envelopes, these arrived back between late March 2010 and August 2011. In all 619 sensors were returned from 321 households $^{8}$ (Fig. 3), which represents a household loss rate of $33 \%$.

Following the surveys, in the winter of 20011/12, face-to-face interviews were conducted with 20 households, which shed a little more light on their heating practices and how these relate to their thermal comfort perceptions and lifestyle. Subsequently, web-based imagery was used to confirm the house type and to determine the external surface areas and the prevalence of extensions, etc.

\section{Weather measurements}

\footnotetext{
${ }^{6}$ The data points bear no direct relationship to the households surveyed but preserve the number and rough location of those interviewed.

${ }^{7}$ Aerial imagery was used to confirm these responses.

${ }^{8}$ Some homes were inadvertently not offered sensors by the interviewer.
} 
Long-term temperature data was available from Leicester City Council's weather station but more detailed and complete hourly weather data for the monitoring period was obtained from De Montfort University (Fig. 4). The location of both sites is in the centre of the map (Fig. 1).

The temperatures from $1^{\text {st }}$ July to $31^{\text {st }}$ August are the focus of this study. During this period, the external temperature varied from $7.9^{\circ} \mathrm{C}$ to a peak of $29.7^{\circ} \mathrm{C}$ and the total solar radiation values reached $968 \mathrm{~W} / \mathrm{m}^{2}$ on $15^{\text {th }}$ July (Fig. 4). The start of the monitoring period was hot. Beginning on $28^{\text {th }}$ June, the average daily temperature exceeded $19^{\circ} \mathrm{C}$ for five successive days reaching $24.1^{\circ} \mathrm{C}$ on July $1^{\text {st }}$ (cf. Hajat's observation that increased deaths occur when the average daily temperature exceeds $19^{\circ} \mathrm{C}$ ) but falling back to $18.8^{\circ} \mathrm{C}$ on July $3^{\text {rd }}$. Thereafter, it was below $19^{\circ} \mathrm{C}$ for all but one day during the rest of the monitoring period. The external temperature during these five days exceeded $25^{\circ} \mathrm{C}$ for 19 hours, with the hottest day having ten hours over 19C (cf. the UK heat wave plan (NHS, 2011), which notes that temperatures over this value lead to increased mortality). The highest daily average temperature recorded in Leicester in the 10 years from 2000 and $2009^{9}$ was $25.8^{\circ} \mathrm{C}$ on $25^{\text {th }}$ July 2006 and it only exceeded $24.1^{\circ} \mathrm{C}$ on 11 days, i.e. only 3 days in 1000 are warmer than July $1^{\text {st }} 2009$. The recorded running mean of the external temperature, $T_{\mathrm{rm}}$, as defined in BSEN15251 (2008) (see below), reached $20^{\circ} \mathrm{C}$ on July $3^{\text {rd }}$. This is similar to the $97^{\text {th }}$ centile value of mean daily temperature in Leicester for 2000 to 2009 of $20.5^{\circ} \mathrm{C}$, (cf. Hajat's observation noted above) but lower than the highest value recorded in Leicester during the 2003 heat wave of $21.4^{\circ} \mathrm{C}$ and the and well below Leicester's highest ten-year $\mathrm{T}_{\mathrm{rm}}$ value of $22.4^{\circ} \mathrm{C}$ on 26th July 2006, when it was over $20^{\circ} \mathrm{C}$ for 13 successive days. Whilst hot for Leicester, the temperatures in early July were modest compared to those recorded in other larger cities during an extreme heat wave (cf. Wright et al's observations above).

Considering the whole period, the average temperatures were $16.2^{\circ} \mathrm{C}$ in July and $16.6^{\circ} \mathrm{C}$ in August compared to the Leicester ten year averages of $17.2^{\circ} \mathrm{C}$ and $17.1^{\circ} \mathrm{C}$ respectively. Thus, overall, the monitored period was cooler than normal for the time of year. The running mean temperatures support this perception; throughout the two month period, the $\mathrm{T}_{\mathrm{rm}}$ value exceeded $16^{\circ} \mathrm{C}$ for $39 \%$ of the time and $18^{\circ} \mathrm{C}$ for $13 \%$ of the time, compared to the Leicester ten year average figures for July and August of 51\% and 23\% respectively.

Given the weather conditions, the measured indoor temperatures will give information about temperatures during a hot spell of weather but not about conditions during prolonged hot weather, i.e. a heat wave. The data will though, provide insight into indoor temperatures, and thus thermal comfort, during cool UK summer weather. The hot spell does however mean that indoor thermal comfort can be examined for a wide range of external temperatures.

\section{Thermal comfort evaluation}

Both static and adaptive criteria for assessing the risk of overheating and thermal comfort in the homes were used in the analysis, partly in order to assess their relative benefits and credibility for this type of analysis and partly to obtain the fullest possible impression of the data. The criteria are applicable to so-called free-running buildings, that is, buildings which are not mechanically heated or cooled; they have been applied only to such spaces in this study.

Static criteria use fixed threshold temperatures that remain the same irrespective of the external conditions or the temperature driven behaviour of building occupants. They are exemplified by those in the Chartered Institution of Building Services Engineers Guide A (CIBSE, 2006). This is the standard most often used in the UK to guide the thermal design

\footnotetext{
${ }^{9}$ As recorded by Leicester City Council in the middle of Leicester.
} 
and performance evaluation of buildings; it gives target temperatures for living rooms and bedrooms of $23-25^{\circ} \mathrm{C}$. The Guide states that "during warm weather $25^{\circ} \mathrm{C}$ is an acceptable temperature" for the living areas of dwellings and it offers a thermal comfort criterion against which to evaluate thermal models' predictions: a limit of " $1 \%$ annual occupied hours over operative temperature of $28^{\circ} \mathrm{C}$ ". Thresholds of $25^{\circ} \mathrm{C}$ and $28^{\circ} \mathrm{C}$ underpin a number of international criteria for evaluating annual overheating risk (e.g. Eppel \& Lomas, 1992; Cohen et al., 1993) with $5 \%$ of hours over $25^{\circ} \mathrm{C}$ or $1 \%$ of hours over $28^{\circ} \mathrm{C}$ being given as allowable annual exceedences. They have been used to assess overheating risk as predicted by thermal models by various CIBSE documents (e.g. CIBSE, 2005).

Concerning bedrooms, the CIBSE guide notes that "thermal comfort and quality of sleep begin to decrease if bedroom temperatures rise much above $24^{\circ} C^{\prime}$ " and that "bedroom temperatures at night should not exceed $26^{\circ} \mathrm{C}$ unless ceiling fans are available", the overheating criterion to be used in association with predicted temperatures is that there should be no more than " $1 \%$ annual occupied hours over an operative temperature of $26^{\circ} \mathrm{C}$ ".

The criteria are intended specifically for assessing the predictions of thermal models, and have been used widely or this purpose. In their modelling study, Peacock et al. (2010) use $28^{\circ} \mathrm{C}$ as a threshold for living rooms and $23.9^{\circ} \mathrm{C}$ at 23:00 for bedrooms, and in their modelling work, Hacker et al. (2008) deemed that a building was overheated if in any year more than $1 \%$ of occupied hours exceeded $28^{\circ} \mathrm{C}$ for living rooms and $26^{\circ} \mathrm{C}$ for bedrooms, which had an assumed occupancy period from 23:00 to 07:00. The NHS heat wave plan used similar criteria, daytime thresholds of $23^{\circ} \mathrm{C}$ and $26^{\circ} \mathrm{C}$ for bedrooms and $25^{\circ} \mathrm{C}$ and $28^{\circ} \mathrm{C}$ for living rooms, to show the predicted effect on temperatures of insulating homes.

Despite their intended usage, others have used the criteria to evaluate measured indoor house temperatures, for example, Wright et al., (2005) used hours over $25^{\circ} \mathrm{C}$ and $28^{\circ} \mathrm{C}$ in their study of temperatures during the 2003 heat wave. Like Hacker et al they used 23:00 to 07:00 as the occupancy period of bedrooms. The current lead author has also used the criteria for the study of measured hospital bedroom temperatures (e.g. Lomas and Giridharan, 2012, Lomas et al., 2012).

To maintain consistency with this body of previous work, the CIBSE threshold temperatures (5\%/25 and $1 \% / 28^{\circ} \mathrm{C}$ living rooms and $5 \% / 24$ and $1 \% / 26^{\circ} \mathrm{C}$ bedrooms) are used in this work to identify spaces with elevated temperatures. However, as these are applied to a measurement period of just 2 months, and not a whole year, values in excess of $1 \%$ and $5 \%$ do not indicate overheating as defined by the CIBSE.

Whilst 'static' criteria are helpful for rapidly comparing temperatures in different homes, in practice, individuals will adapt to changing temperatures: by wearing more or less clothing, taking hot or cold drinks, being more or less active, or by adapting their surroundings, for example, controlling ventilation by opening and closing windows and trickle vents and creating shading by closing curtains and blinds. Thus, adaptive thermal comfort criteria may be much more appropriate for assessing the internal conditions in homes.

In summer, UK homes are likely to be free-running i.e. not heated or mechanically cooled. The internal temperature therefore drifts with the change of external temperature and the expectations of people differ similarly; they wear less clothing on hotter summer days, for example. Thus, in summertime, people are likely to be better adapted to conditions in freerunning buildings and find them more comfortable than those in artificially cooled spaces ${ }^{10}$.

Contemporary adaptive thermal comfort standards provide comfort envelopes that drift with the external temperature. The most relevant standard for UK dwellings is British Standard

${ }^{10}$ The chill of entering air-conditioned spaces on a summer day will be familiar to many. 
and European Norm BSEN15251 (British Standards Institute, 2008), which "specifies methods for long term evaluation of the indoor environment obtained as a result of calculations or measurements" "11 and is applicable to "single family houses". The standard provides comfort envelopes with thresholds that increase at a rate of $0.33 \mathrm{~K}$ per $\mathrm{K}$ as the running mean of the external temperature $\left(\mathrm{T}_{\mathrm{rm}}\right)$ increases within the range $10<\mathrm{T}_{\mathrm{rm}}<30^{\circ} \mathrm{C}^{12}$.

The Category I envelopes define a $4 \mathrm{~K}$ range of temperatures for each value of $\mathrm{T}_{\mathrm{rm}}$; Cat. II, a wider 6K range; and Cat. III, a wider envelope still 8K (Fig. 5). These are defined as Cat. I

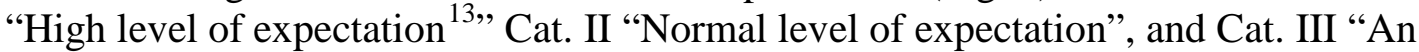
acceptable, moderate level of expectation and may be used for existing buildings”. Cat. IV, "Values outside the criteria", "should only be accepted for a limited part of the year". Applying standard comfort theory calculations, Cat. I, II, III correspond respectively to 6\%, $10 \%$, and $15 \%$ of predicted dissatisfaction in normal health people, see PPD in ISO 7730 (International Standards Organisation, 2005) $)^{14}$. The envelopes are undefined below $\mathrm{T}_{\mathrm{rm}}=15^{\circ} \mathrm{C}$ and so in keeping with previous work, it is presumed in the analyses conducted herein that they run horizontally for $\mathrm{T}_{\mathrm{rm}}$ values below $15^{\circ} \mathrm{C}$.

The CIBSE Guide A gives adaptive thermal comfort envelopes that are identical to the BSEN15251 Cat. I envelopes, but applicable down to a $\mathrm{T}_{\mathrm{rm}}$ value of $8^{\circ} \mathrm{C}$ (Fig. 5). The US standard, ASHRAE 55 (ANSI/ASHRAE, 2010) provides adaptive envelopes that are based on the monthly mean external temperature, $\mathrm{T}_{\mathrm{mm}}$, which increases at a rate of $0.31 \mathrm{~K}$ per $\mathrm{K}$ over the range $10<\mathrm{T}_{\mathrm{mm}}<33.5^{\circ} \mathrm{C}$ (Fig. 5). Wright et al. (2005) used an earlier form of this envelope (De Dear \& Brager, 2001) to evaluate indoor temperatures in the 2003 heat wave. It is evident therefore that adaptive standards, although relatively recent are gaining widespread acceptance.

The important thing about the adaptive standards is that they are derived from field measurements in free-running buildings; mostly office buildings. They are thus inherently suited to, and recommended for, evaluating measured data under circumstances in which occupants are free to respond to internal and external temperature stimuli. The standards also recognise that adaptation takes place over a relatively short time period, as determined by $\mathrm{T}_{\mathrm{rm}}$ or, in the ASHRAE case, $\mathrm{T}_{\mathrm{mm}}$, thus people will adapt to gradual temperature changes and to spells of hot weather, but with a time lag; which is consistent with the observed higher frequency of deaths in the first few days of a heat wave (NHS, 2011).

The current lead author has also used the BSEN15251 method to evaluate measured hospital bedroom temperatures (Lomas and Giridharan, 2012, Lomas et al, 2012) and the method is used here for assessing both living rooms and bedrooms; interestingly, the room type doesn't influence the category boundaries used. Importantly, unlike the static criteria, both warm and cold thermal discomfort can be assessed, and over any time period. The standard does not place strict limits on the allowable exceedences of the category boundaries, although five methods of quantifying exceedences are offered. Of these, the simplest is the percentage of hours outside a category boundary. In this work, $5 \%$ of hours above the Cat II boundary is used as a marker for warm discomfort and 5\% below the Cat III as a marker of cold discomfort.

\footnotetext{
${ }^{11}$ Authors' underlining.

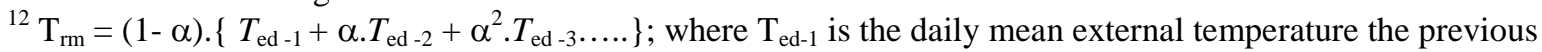
day, $\mathrm{T}_{\text {ed-2 }}$ the daily mean external temperature two days ago, etc., and $\alpha$ has a recommended value of 0.8 .

${ }^{13}$ This is the recommended category for spaces "occupied by very sensitive and fragile persons with special requirements like handicapped, sick, very young children and elderly persons".

${ }^{14}$ The standard also offers temperatures for the winter heating season of 21,20 and $18^{\circ} \mathrm{C}$ for Cat. I, Cat. II and Cat. III respectively.
} 


\section{Inspection of the measured data}

The data from the returned sensors was downloaded and attached to the corresponding household interview data, with the exception of 23 sensors which would not download or for which the interviewers had recorded the incorrect serial numbers making it impossible to attach the sensor data to a particular property. Thus data was available from 312 households of which 284 had both living room and bedroom data, 18 for living room only and 10 for bedroom only: 596 data traces in all.

The hourly data was plotted for the period $1^{\text {st }}$ July to $31^{\text {st }}$ August 2009 and inspected by eye. This immediately revealed a number of anomalies, in particular sensors that had not been placed correctly or were not working. These data were excluded from the data set but only when there were clear grounds for exclusion; when there was uncertainty, the data remained in the dataset. Data were excluded when: both sensors were recording identical temperatures (consistent with a situation where sensors had been left together - 18 sensors); step changes in the temperature profile occurred (consistent with a sensor being moved - 10 sensors); sensors were recording values very close to external temperature (consistent with them having been placed outside or in a porch - 3 sensors); extreme responses, that correlated with solar radiation, were recorded (consistent with the sensor being left in sunlight - 12 sensors); and when temperature profiles were extremely unresponsive to external temperature (consistent with sensors being placed in a container, cupboard or drawer etc - 5 sensors).

In addition to these exclusions, data from 13 sensors indicated there were problems with the internal clock. Finally, some temperature traces suggested periods of abnormally low temperatures, possibly because the houses were unoccupied, a summer holiday perhaps (4 houses). Excluding the 35 households where both the living room and bed room temperatures appeared to be in error left a data set of 282 homes with useable data: 234 had data from both rooms; 30 from just the living room; and 18 from just the bedroom (Fig. 3).

Visual inspection of the temperature traces indicated that some spaces were free-running but that others were probably heated at some time during the two month period. Since the main aim is to analyse free-running spaces, any home that might have been heated (in either space) was separated out. This left 186 homes for which both rooms were free-floating, plus 26 freefloating living rooms and 18 free-running bedrooms (in these homes data was unavailable from the other space): i.e. data from 230 homes in total, 82\% of the sample of 282 (Fig. 3).

In the remaining 52 homes (18\%), there may be some form of heating in one or other of the rooms at some time during the monitoring period. However, it was difficult to determine unambiguously whether the changes in sensor temperature were due to space heating or to some other heating affect; for example, exposure to radiant heat sources (such as tungsten halogen lights) or a thermal plume from a convective source (such as a radiator or a warm electrical device). In cases of doubt the temperature records were ignored, thus ensuring that the remaining data was from rooms which, as far as the authors could tell, were definitely, and probably deliberately, heated. This analysis left 3 homes in which both spaces were heated, plus 28 with heated living rooms and 7 with heated bedrooms (Fig. 3) ${ }^{15}$.

There is substantial difference between number of 481 homes (with 951 sensors) for which data was potentially available and the number of useable temperatures traces i.e. 457. This

\footnotetext{
${ }^{15}$ In these homes, the non-heated room either did not yield data or it was free-floating. However, these free-floating rooms were not, as noted above, included in the free-floating sample, as the flow of heat from the heated room could mean the space was not truly free-running.
} 
$52 \%$ data loss is primarily due to the non-return of sensors (a 36\% loss) and data anomalies that were mostly likely to be due to misplacement of sensors. Clearly, the sensor placement protocol is an important factor in temperature surveys and it is recommended that, to avoid misplacement, a trained individual should locate them. The cost of doing this could however be high and insistence on this approach might compromise data collection, if occupants are reluctant to have others enter some rooms. Further, there no guarantee the sensors would remain undisturbed throughout the measurement period.

The distribution of house types, household sizes and tenure types in the sample of 268 homes reflected that of the city as a whole (Table 1 ), although the percentage owning their property either outright or with a mortgage (68\% in the sample of 268 homes) seems to be much greater than in the city as a whole (58\%) with the percentages renting being less, $30 \%$ in the sample and $40 \%$ in the city as a whole. However, the data for the city is from the 2001 census (ONS, 2010) and new owner-occupied homes have been built and some previously rented will have been bought, thus our sample might actually be representative of Leicester today.

\section{Data Analysis: heated homes}

The heated spaces displayed large and frequent temperature changes, often up to the same peak value (the set-point perhaps) and sometimes following a regular pattern (evidence of a timer in use). In homes where both the living room and bedroom were heated, the temperature changes were in synchrony suggesting a central heating system was switched on. As an illustration, Figure 6 shows a regular pattern of night time heating in the bedroom of a rented flat occupied by a single elderly person; there is also evidence of heating in the living room after the internal temperature fell below $23^{\circ} \mathrm{C}$ in early August.

The temperatures in the 31 heated living rooms is compared with that in the 212 free floating living rooms by plotting the percentage of hours between $08: 00$ and 22:00 over $28^{\circ} \mathrm{C}$ and $25^{\circ} \mathrm{C}$ (Fig. 7). Amongst the warmest 23 homes (i.e. 9\% of the sample), where the living room temperature exceeded $25^{\circ} \mathrm{C}$ for more than $20 \%$ of the time, $57 \%$ (13 homes) were heated. The average temperature in the 31 heated living rooms was $23.5^{\circ} \mathrm{C}$ although the hottest room had a mean of $28.2^{\circ} \mathrm{C}$ and a maximum of $33.7^{\circ} \mathrm{C}$. The temperature in this room exceeded $25^{\circ} \mathrm{C}$ for $99 \%$ of the time and $28^{\circ} \mathrm{C}$ for $67 \%$ of the time. In the 10 homes with heated bedrooms, the overall mean temperature between $23: 00$ and $07: 00$ was $23.4^{\circ} \mathrm{C}$ and the hottest bedroom reached $37.4^{\circ} \mathrm{C}$ ! Clearly some people like their home to be very warm.

An elderly couple lived in the tenth warmest house, a post-war semi, which was heated such that the living room temperature exceeded $25^{\circ} \mathrm{C}$ for $40 \%$ of the summer (Fig. 7). In interview the woman of the household, who was over 60 , said that "she felt the cold" so "always has the heating on", in fact, a separate heater was provided for her to use when the central heating was turned off.

All statistical analysis of the heated homes was undertaken using the Pearson's chi-squared test based on 2x2 contingency tables (e.g. Field, 2005). This revealed that significantly more semi-detached homes were heated $(\mathrm{p}<0.05)$. More importantly, in 13 of the heated homes (i.e. $34 \%$ of them) the occupants were over 70 years of age (with 7 of them living alone). This is significantly more over 70 's $(\mathrm{p}<0.02)$ than the $20 \%$ that would be expected if equally distributed across heated and unheated homes.

The greater tendency for elderly people to heat their homes in summer could be, in combination with hot weather, quite literally, a lethal combination. The heating will tend to pre-load any exposed thermal mass rendering less able to absorb heat during a heat wave. This will lead to even higher internal temperatures than would be the case without heating. Further more, because thermal sensation deteriorates with age, older people are particularly 
susceptible to elevated temperatures (e.g. Novieto and Zhang, 2012). They may also be less likely to take adaptive measures, due to illness etc, further exacerbating their situation.

This is thought to be the first study to reveal this tendency for some householders to heat their home in summer. The observation suggests that heat wave public awareness campaigns should include the simple advice to turn off heating systems; this message should be clearly and explicitly incorporated in the NHS heat wave plan for example (NHS, 2011) and delivered as part of the regional Level 2 heatwave warning.

\section{Data analysis: unheated homes}

Within the sample of 230 free-running homes, temperature data was available for both rooms in 186 homes, for the living room only in 26 homes and the bedroom only in 18 homes, thus data was analysed for a total of 212 living rooms and 204 bedrooms (Table 1).

In general, the free-running rooms exhibit drifts in temperature in response to the changing external temperature but with attenuation and some time lag (Fig. 8). Overlaid on this general behaviour were more rapid temperature rises due to solar gains and internal heat gains from appliances etc; the latter being most obvious in living rooms in the evenings.

Across all 212 free-running living rooms, the average mean temperature recorded between 08:00 and 22:00 across the two-month period was $22.2^{\circ} \mathrm{C}$; the range in the means was from $25.2^{\circ} \mathrm{C}$ to $19.0^{\circ} \mathrm{C}$. The highest single hourly temperature recorded in a living room was $32.6^{\circ} \mathrm{C}$ and the lowest $14.8^{\circ} \mathrm{C}$. The mean temperatures recorded in the 204 bedrooms between 23:00 and $07: 00$ in the two month period varied from $25.1^{\circ} \mathrm{C}$ to $18.8^{\circ} \mathrm{C}$ with an average mean of $22.4^{\circ} \mathrm{C}$. The highest single hourly temperature recorded in any bedroom was $35.0^{\circ} \mathrm{C}$ and the lowest $14.1^{\circ} \mathrm{C}$. Thus, despite the milder weather conditions, the hottest free-running Leicester homes had peak temperatures comparable to those recorded in the 2003 heat wave in Manchester; $30.0^{\circ} \mathrm{C}$ in a living room and $36.0^{\circ} \mathrm{C}$ in a bedroom.

In the 186 homes with measurements in both rooms, the greatest differences between the mean living room temperature and the mean bedroom temperature were $+3.7^{\circ} \mathrm{C}$ (living room warmer) and $-3.5^{\circ} \mathrm{C}$ (bedroom warmer). There were 76 homes where, on average, the living room was warmer than the bedroom and 111 where, on average, the bedroom was warmer (Fig. 9). For many homes there was no clear tendency towards either a warmer bedroom or a warmer living room. However, in 48 homes the living room was consistently warmer; i.e. for $90 \%$ of the time or more. Significantly, more of these were built between 1945 and 1964 than would be expected if evenly distributed $(\mathrm{p}<0.02)$. In 26 homes, the bedroom was consistently warmer. These included significantly more households with just one or two members (as typifies the elderly) and significantly more modern, post-1980s homes ( $<<0.04)$.

\section{Analysis of free-running rooms: CIBSE static criteria}

The percentage of hours over $25^{\circ} \mathrm{C}$ and $28^{\circ} \mathrm{C}$ are shown for the living rooms in Figure 10 and over $24^{\circ} \mathrm{C}$ and $26^{\circ} \mathrm{C}$ for the bedrooms in Figure 11 . Chi-squared tests were used to understand if the known socio-technical characteristics of the house and household had a significant affect on whether the $1 \% / 28^{\circ} \mathrm{C}$ or $5 \% / 25^{\circ} \mathrm{C}$ criterion was exceeded. Significance is reported at the $90 \%(\mathrm{p}<0.1)$ and $95 \%(\mathrm{p}<0.05)$ levels (Table 2$)$.

Of the 212 living rooms, 122 (i.e. 58\%) exceed the $5 \% / 25^{\circ} \mathrm{C}$ criterion when considering the whole day (08:00 - 22:00) (Fig. 10) and 133 (i.e. 63\%) when considering the evening only 
$(18: 00-22: 00)^{16}$; i.e. when living rooms are more likely to be occupied with additional internal heat gains. Considering the $28^{\circ} \mathrm{C} / 1 \%$ criterion, 58 of the homes (i.e. $27 \%$ ) exceeded this when considering the whole day and 64 (i.e. 31\%) when considering just evening hours.

The statistical analyses revealed that there were significantly more flats with over $1 \%$ of hours above $28^{\circ} \mathrm{C}$ than other house types, i.e. 13 (48\%) when considering either the whole day or just the evenings $(p<0.05)$. Flats were also significantly more likely to have living rooms with over $5 \%$ of hours above $25^{\circ} \mathrm{C}(\mathrm{p}<0.1)$. This finding aligns with observations of previous researchers and comments in the national heat wave plan; that top floor flats are at particular risk. Other analysis revealed that just $5 \%$ of the flats were occupied by a person over 70 , much less than in the whole sample of free-running rooms $(17 \%)$. In the $4 \mathrm{M}$ sample of homes therefore, the elevated temperatures found in flats does not disproportionately expose more elderly people to hot conditions. The living rooms of solid wall properties were found to be significantly less warm, as judged by either criterion, and by both whole day and evening only analyses $(\mathrm{p}<0.05)$. Again this aligns with the findings of others as derived from simulation, i.e. that exposed thermal mass confers protection against elevated temperatures. Other isolated instances of significant results also arose but tenure and loft insulation level was never a significant factor (Table 2).

Considering the 204 bedrooms, the most obvious result is that many of them are very warm during the night (23:00-07:00); almost $20 \%$ are over $25^{\circ} \mathrm{C}$ for $30 \%$ of the time, with seven exceed $25^{\circ} \mathrm{C}$ for $60 \%$ of the time (Fig. 11). Clearly, therefore, the vast majority have temperatures that exceed both the $24^{\circ} \mathrm{C} / 5 \%$ and the $26^{\circ} \mathrm{C} / 1 \%$ criteria; $92 \%$ and $88 \%$ respectively. Bedrooms in modern (post-1980) homes were found to be significantly cooler, as judged by either criterion, than those in houses built earlier; perhaps the increased likelihood that they have loft insulation is a factor.

\section{Analysis of free-running rooms: adaptive thermal comfort criteria}

The application of the static criteria enabled identification of the socio-technical characteristics that lead to rooms being significantly warmer than others. The criteria also gave the impression that some rooms, notably bedrooms, were rather warm for much of the time (over $25^{\circ} \mathrm{C}$ ), despite the overall cool summer conditions experienced. Analysis using the adaptive thermal comfort standard paints a rather different picture.

Plotting the measured hourly temperatures against the running mean of the daily average external temperature $\left(\mathrm{T}_{\mathrm{rm}}\right)$, as demanded by the BSEN15251 approach, produces vertical strings of values for each day. There are 8 values for the bedroom (each hour from 23:0007:00) and 16 for each living room (08:00-22:00) plotted in Figure 12, a warmer house, and Figure 13, a cooler house. Both houses clearly show a trend towards higher indoor temperatures at higher $T_{\mathrm{rm}}$ values, as one would expect. The range of temperatures on any given day could be large; up to $7 \mathrm{~K}$ or so at higher $\mathrm{T}_{\mathrm{rm}}$ values (Fig. 12), which occurred at the start of the monitoring period (Fig. 4). In both homes the overall impression is of internal temperatures that tend to be towards the lower category boundaries, rather than the upper boundaries.

In these particular homes, the living room tends to be warmer than the bedroom at low external temperatures (as measured by $\mathrm{T}_{\mathrm{rm}}$ ) but less obviously so at higher $\mathrm{T}_{\mathrm{rm}}$ values. Whereas the warmer house had internal temperatures above the Cat III upper threshold when $\mathrm{T}_{\mathrm{rm}}$ exceeds c18 ${ }^{\circ} \mathrm{C}$ (Fig. 12) this was not so for the cooler house, which tended to have

\footnotetext{
${ }^{16}$ Not shown herein.
} 
bedroom temperatures well below the Cat III threshold, especially when $\mathrm{T}_{\mathrm{rm}}$ was less than $18^{\circ} \mathrm{C}$. The changes in the relative difference between the living room and bedroom temperatures with external temperature may be worthy of further study.

Clearly, it is impractical to show all free-running home temperatures as individual plots, so the approach suggested in BSEN15251 is adopted whereby the percentage of time in each category is plotted as a bar chart (Figs. 14 and 15) ${ }^{17}$. These, clearly show the overriding tendency for cool, rather than warm, temperatures during the monitoring period; temperatures that for nearly all homes would be classed as uncomfortable using the BSEN15251 criterion that there should be no more than $5 \%$ of hours outside a chosen category boundary; with the Cat III '.... moderate level of expectation, may be used for existing buildings' or possibly Cat II 'normal level of expectation' boundary being applicable to homes. For example, considering firstly Cat II, there was just 1 living room and 5 bedrooms (2\%) with more than $5 \%$ of hours above the upper threshold, but 136 living rooms (64\%) and 144 bedrooms (71\%) with more than $5 \%$ of hours below the Cat II lower threshold. In fact, there were 73 living rooms (34\%) and 99 bedrooms (49\%) below the Cat III lower threshold for more than $5 \%$ of the time ${ }^{18}$. The greater occurrence of cool bedrooms is to be expected, of course, as the temperatures plotted are for the night time.

The statistical analysis of these data (Table 3) shows that there were significantly fewer living rooms and bedrooms in flats with more than $5 \%$ of hours below the lower Cat II and Cat III boundaries than in other house types; which is consistent with their tendency to be warmer, as judged by the static criteria. In contrast, there were significantly more detached homes with more than $5 \%$ of hours below the Cat II and III boundaries; perhaps the additional external wall area contributes to this ${ }^{19}$.

Significantly more solid wall homes, had more than $5 \%$ of hours below the Cat II $(p<0.05)$ and Cat III $(\mathrm{p}<0.1)$ thresholds. These results are consistent with the lower occurrence of high temperatures as judged by the static criteria. Also, significantly more homes built between 1900 and 1919 had over 5\% of hours below the Cat III threshold $(\mathrm{p}<0.05)$, these homes tend to have solid walls. Conversely, there were fewer living rooms in homes with insulated (filled) cavity walls that had more than $5 \%$ of hours below the Cat II standard $(p<0.05)$. Taken together, these results are consistent with the expectation that better insulated homes will be warmer.

Considering occupant age, significantly more living rooms in homes with inhabitants over 70 had more than $5 \%$ hours below the Cat II boundary than for other age categories ( $<<0.1$ all day analysis, $\mathrm{p}<0.05$ evening only analysis). Interestingly, this is the only significant result related to those over 70, for either static or adaptive criteria; and it suggests their houses are cooler not warmer (cf. concerns about the elderly and heat waves). One reason for this result may be that, at least in the 4M sample of homes, significantly more old people lived in detached homes and end terraces $(\mathrm{p}<0.05)$ than in other house types; and these tend to be significantly cooler.

The static criteria and adaptive criteria taken together paint a consistent picture of freerunning buildings - homes which tend to have more external wall area and poorer insulation

\footnotetext{
${ }^{17}$ Data are ordered from left to right by the percentage of time within the Cat I boundaries.

${ }^{18}$ Living room figures quoted here are for the period 08:00 to 22:00, the corresponding values for the evening only 18:00 to 22:00 are: 116 with more than 5\% hours below Cat II and 48 with more than 5\% below Cat III.

${ }^{19}$ These were estimated from Google imagery.
} 
standards tend to be cooler than others, flats, which tend to have a small external wall area, tend to be warmer ${ }^{20}$.

Concerning the adaptive thermal comfort standard, the important conclusion from this study is, of course, that in cool summers most UK homes have internal temperatures which, as judged by the BSEN15251 criterion, would be considered uncomfortably cool. Because heating systems could easily have been turned on if the occupants were uncomfortably cold (they were turned on in the heated homes analysed above), they must, presumably, have chosen to live in at the temperatures measured. The appropriateness of the BSEN15251 adaptive comfort model to UK homes is thus brought into question; the matter is discussed below.

\section{The applicability of static and adaptive methods of assessing measured indoor temperatures}

Given that this paper presents, to the authors knowledge, the first attempt to apply the BSEN15251 method to a large sample of free-running UK houses, it is useful to dwell on the value of the method and its likely validity.

Firstly, it is apparent that the method has clear advantages over the static criteria which are: intended mainly for assessing model predictions; intended for assessing whole years of data; able to judge only high and not low temperatures; insensitive to different persons comfort perception; and are unresponsive to individuals' short term (daily), medium term (seasonal) or long term (climate change) thermal comfort adaptations. Whilst useful for ranking the occurrence of elevated room temperatures, as in this paper, the static criteria cannot credibly indicate whether or not measured temperatures in homes are, or are not, acceptable (or dangerous).

In contrast, adaptive thermal comfort methods, like BSEN15251, are specifically intended for assessment of buildings in use (as well as for assessing predicted values). They can examine whether temperatures are likely to be perceived as too warm or too cool. In this work this proved especially valuable as it presented the overriding impression that the monitored spaces were generally cool rather than warm. Adaptive methods are also, in principle, able to accommodate individuals' adaption to warm and cool external conditions and the four category bands (I, II, III, and IV) suggest that it can be used for persons (or households - see below) with different temperature tolerances. The method encourages the plotting of temperatures (Figs. 12 and 13) which clearly distinguish one day's values from another's. This, together with the overlaid category boundaries, helps give an intuitive understanding of rooms' temperatures. The capability to summarise results in a single plot (e.g. Figs. 14 and 15 ) is clearly advantageous.

The key question though, is whether the adaptive method is valid for deciding whether freerunning UK homes are indeed uncomfortably cold or hot. The method has, after all, been developed overwhelmingly using data collected in offices ${ }^{21}$. In such buildings, there is a mix of persons with different thermal comfort perceptions and so comfort requirement and the internal environment are designed, e.g. by providing opening windows, fans etc, in order that most of the people can be comfortable most of the time. Hence, the BSEN15251category

\footnotetext{
${ }^{20}$ Other isolated significant results can be seen in Tables 2 and 3 but they do not shape into any obvious pattern and they do not contradict the overall picture painted here.

${ }^{21}$ For example, the work within the EU SCATS project (McCartney and Nicol, 2002) and a global data base of 21,000measurements, primarily from office buildings, which underpins the ASHRAE adaptive standard (de Dear, 1998).
} 
thresholds define the percentage of people likely to be dissatisfied by temperature deviations outside the thresholds.

Homes are different in many ways from offices, topologically, they have a much larger surface area to volume ratio thus it is easy for all occupants to adjust windows, blinds and other envelope devices intended to enable thermal adaptation. It is easier also to access outdoor spaces, enabling flow between indoors and outdoors. Homes tend also to be much less densely occupied, leading to lower overall internal heat gains than in offices. Constructionally, UK homes tend to be poorly insulated and leaky. Together, in the UK climate, all these create a tendency for homes to be naturally cool, and thus one might imagine occupants that are adapted to cooler living conditions.

Most home owners, unlike office dwellers, are also directly responsible for heating energy bills, and, especially in times of rising energy costs, are concerned about these. Thus in the UK, many households tend to turn off their heating system after the first prolonged spell of warm weather. (One energy conscious householder that was interviewed simply used a portable electric heater when he was cold placing it next to his arm chair in the living room.) The practice of turning heating systems off in summer is widespread, perhaps because many central heating systems work poorly in mild weather, boilers are then oversized, there is no external temperature compensation, and thermostat control is poor. Homes thus rapidly overheat, which is perceived as a waste of energy ${ }^{22}$. The interviews with householders revealed a reluctance to fiddle with heating controls, especially amongst the elderly, because people didn't understand how they worked. Thus in some homes the heating stayed on (as noted above) in most it was simply either on (in winter) or off (in summer). As one occupant put it "it is too much hassle to change the timer setting to fit with my shifts as it would mean changing it every week".

Whilst there are geometrical, constructional and energy system differences between offices and homes, the nature and behaviour of the occupants is perhaps the most notable feature. Much has been written by others about thermal behaviours in homes (see for example the BR\&I special issue 'comfort in a lower carbon society', and the works referenced therein, Shove et al, 2008). Here just a few observations are made in the context of adaptive standards and their applicability.

Firstly, we might observe that home occupants have a much wider range of ages than is typical in offices, from the very young to the very old. There primary concern is not comfort for sedentary work, but, not infrequently, comfort for health. For example, as householder in our study revealed " my wife was very ill so the house was always comfortably warm for her" and "I have cancer so keep the house warm so as not to risk falling ill”.

Home occupants are usually much more closely related to each other than office workers. They may well have strong generic similarities and shared life experiences and so predispositions to seek similar temperatures to achieve comfort. Indeed, differences in comfort perception are worthy of remark, for example, from or interviewees "my husband tends to feel the cold" and "she feels the cold much more than I do". These remarks also portray an understanding and concern for another's comfort. Parents are most attentive to the thermal comfort of children. Households may also be doing similar tasks and so wearing similar clothing and perhaps generating comparable levels of metabolic heat. They may also take hot and cold drinks breaks together, again leading to similar internal rates of heat generation. Further, especially in summer, individuals might continually move between indoor and outdoor spaces and so be dressed for such transitions. (This mix of inside and

\footnotetext{
${ }^{22}$ One wonders also of the habit might be culturally engrained, originating from ties back to times when creating heat was a time consuming and messy business (lighting coal fires).
} 
outside living also suggests that some times internal temperature may not be at all important.) Such behaviours would not occur in offices. All these observations lead one to propose therefore, that a household might be viewed as a single 'organism' with its shared perception of what is, and is not, comfortable. Comfort criteria might thus need to apply to a household rather than each individual in it. It is not clear then what the meaning of the PPD levels associated with the category boundary lines in the BSEN15251 might mean in the context of homes, neither is it clear whether $5 \%$ exceedences of any chosen category is relevant.

Considering the clothing and activity alone as adaptive measures, it can be shown that comfort may be readily attained in homes at temperatures well below the Cat III envelope. Using standard thermal comfort calculations, at a temperature of $15^{\circ} \mathrm{C}, 93 \%$ of normal healthy individuals, if seated and wearing normal summer clothing, would feel uncomfortable (0.6Clo). However, if doing light domestic work, this would fall to $28 \%$ and if these persons then wore extra sweaters (1.2Clo) the value would fall to about $5 \%$ dissatisfied; which is the lowest dissatisfaction level attainable ${ }^{23}$. Thus, in a domestic setting, individuals may be doing tasks and wearing clothing that means temperatures of just $15^{\circ} \mathrm{C}$ will be comfortable. In the $4 \mathrm{M}$ study reported here the lowest temperature recorded in any home was $14.8^{\circ} \mathrm{C}$.

Unlike offices, homes are full of niches with different local temperatures and, actually, different insulating properties. A deep padded arm chair in the sunlight from a window will provide a haven of comfort and warmth quite different from the (measured) temperature and thus comfort offering of the room as a whole. People are expert at seeking out such oases of warmth and delight ${ }^{24}$. This plethora of adaptive opportunity enables the different comfort perceptions and activity levels of household members to be accommodated without inconvenience or resort to heating. As an interviewee put it "my wife feels the cold more than me so tends to wear cardigans and jumpers around the house”. Homes are equipped specifically to provide personal comfort opportunities; offices are furnished for other purposes.

All this also raises the question of whether the BSEN15251 lower category boundaries should, for homes, continue downwards to $\mathrm{T}_{\mathrm{rm}}=8^{\circ} \mathrm{C}$, as the CIBSE boundaries do, rather than running horizontally from $\mathrm{T}_{\mathrm{rm}}=15^{\circ} \mathrm{C}$ (as in Figs. 12 and 13). If they did, the lower threshold of Cat III would be $c 18^{\circ} \mathrm{C}$ (at $\mathrm{T}_{\mathrm{rm}}=8^{\circ} \mathrm{C}$ ), and $18^{\circ} \mathrm{C}$ would be quite comfortable for an individual doing light house work wearing a sweater (0.9Clo).

These observations lead to the proposition that, compared to office environments, individuals living in the same house may have similar comfort perception, may undertake a much wider range of activities, may have a wider range of acceptable clothing options, and may have much more adaptive opportunity; at times the internal temperatures may not be at all important to them. Thus, whilst the BSEN15251 method has great promise conceptually for assessing comfort in free-running homes it isn't clear how it might be used in practice. (This leads one to speculate also about how best the method might be used in the design of new homes, but use in prediction is for others to consider more deeply).

Looking forward, although some studies of comfort in homes have been undertaken (e.g. Peeters et al 2009), the work reported herein suggests that there is much more to learn about

\footnotetext{
${ }^{23}$ Calculation using the Fanger method as described in ISO 7730 (International Organization for Standardization, 2005). For activity levels of 1Met (70W/m2), sedentary, and 100Met (100W/m2) for light domestic work, see INNOVA(2002). The same source gives for summer clothing 0.6Clo (briefs, thin socks, light shoes, plus normal long-sleeve shirt and trousers) and with an normal sweater (0.9Clo) and two extra sweaters (one thin and one thick) 1.2Clo. The calculations assume low air speed $(0.1 \mathrm{~m} / \mathrm{s}), 50 \%$ relative humidity and equal radiant and air temperatures.

${ }^{24}$ As are household pets, especially cats.
} 
comfort in homes, and especially that there is a crucial need for more detailed measurement. Here single temperatures were recorded in just two rooms, which may not reflect the conditions experienced by the occupants at any given time, and there were no clothing or activity level records. New technologies are opening up avenues for such integrated investigations (see e.g. Gautier, 2011), and the results of that work will contribute to a much needed deeper understanding of comfort in homes. A multi-disciplinary approach to the matter combining the insights of physicists, physiologists, social scientist etc is essential.

\section{Conclusions}

The conclusions are based on data measured between July $1^{\text {st }}$ and August $31^{\text {st }} 2009$ in the city of Leicester, UK, as part of the 4M project. This was a generally cool period but with one five day hot spell. Temperatures are reported for the living room or bedroom of 230 homes that were free-running and 38 that were heated. The thermal comfort in the free-running buildings was assessed using both static and adaptive thermal comfort criteria. This is believed to be the first large-scale study of UK house temperatures that as been reported. Conclusions cover primarily the thermal comfort of the homes but also the appropriateness of static and adaptive thermal comfort criteria.

The "drop and collect" method for measuring internal house temperatures resulted in useable data from just $48 \%$ of the spaces monitored. This was because either the households did not return the sensors (a 35\% sensor loss) or because the data was corrupted or unreliable. This was a well-conducted study, using a professional survey company. Such a high loss of data is expensive. Of the usable data, it was sometimes unclear which rooms were being purposely heated and which were warmed by other sources of internal gain, lights, TVs etc. This was exacerbated because households were asked to place the temperature sensors and some could have been located rather close to such sources of internal heat gain. One clear recommendation of this study is that reliable space temperature monitoring is only likely to be possible if temperature sensors are located by trained members of the study team.

Those households with persons aged over 70 were significantly more likely to heat part of their home in summer than those with younger inhabitants; some were heated to high temperatures. This is particularly worrying as it will exacerbate the tendency for their homes to overheat in warm weather and it is the aged that suffer most during such weather. It is suggested that the National Health Service heat wave plan includes explicit advice that heating systems and other sources of heat should be turned off during warm weather.

Despite the rather cool summer, some free-running homes were extremely warm. The hottest free-running homes had peak temperatures in the living room and bedroom comparable to those recorded in Manchester in the 2003 heat wave, despite the external conditions being less severe. Around $15 \%$ of bedrooms had temperatures over $26^{\circ} \mathrm{C}$, which is deemed to be a temperature that inhibits sleep, for more than $30 \%$ of the summer nighttime hours.

The statistical analyses of the free-running homes revealed that there were significantly more flats, than other house types, with more than $1 \%$ of hours over $28^{\circ} \mathrm{C}(\mathrm{p}<0.05)$ and more than $5 \%$ of hours over $25^{\circ} \mathrm{C}(\mathrm{p}<0.1)$, which aligns with observations of previous researchers and comments in the national heat wave plan. The living rooms of solid wall properties were found to be significantly less warm, as judged by either criterion $(p<0.05)$. Again this aligns with the findings of others.

A comparison of the average living room and bedroom temperatures in the free-running homes revealed that significantly more of the bedrooms in modern post-1980's homes were consistently warmer than the living room $(\mathrm{p}<0.04)$ and in homes built between 1945 and 1964 the living room was consistently warmer than the bedroom $(\mathrm{p}<0.02)$. 
Overall however, analysis using the BSEN15251 adaptive thermal comfort standard, painted a picture of rooms being generally rather cool. Just 1 living room and 5 bedrooms had more than $5 \%$ of hours with temperatures above the Cat II, normal expectations, thermal comfort envelope. In contrast, there were $64 \%$ of living rooms and $71 \%$ of bedrooms in which temperatures were below the lower Cat II threshold more than 5\% of the time; in fact, $34 \%$ of living rooms and $49 \%$ of bedrooms has temperatures below the Cat III envelope more than $5 \%$ of the time. There were however, significantly fewer cool bedrooms and living rooms in flats than in other home types.

Taken together, the static and adaptive criteria indicate that free-running living rooms in detached homes, in homes with solid walls, and in homes built before 1919 (which tend to have solid walls), were significantly cooler than in other house types. Interestingly, in this study, significantly more over 70's tended to live in detached homes and end terraces predisposing them to experience cool, rather than warm, conditions. Homes with cavity wall insulation tended to be significantly less cool than those without such insulation. There results concur with the findings of others' as derived from modelling studies.

The evidence from this study is that adaptive thermal comfort methods are much more useful and insightful for assessing indoor thermal comfort in homes than static methods. However, the results indicate that occupants of UK homes do not operate them, at least during cool summer weather, in order to achieve the internal temperatures anticipated by the BSEN15251 thermal comfort standard. Occupants seem content with low internal temperatures when external temperatures are low, and heating systems therefore remain switched off. The possible reasons for this are discussed at length, but essentially it is argued that the BSEN15251 method has been derived primarily from studies of offices, whereas homes are quite different. At home people operating at very different activity levels, with freedom in their choice of clothing, with due consideration for others' thermal state, and in an environment specifically designed to provide abundant adaptive opportunity; they are also concerned about energy costs. Given this, it is demonstrated that temperatures well below the BSEN15251 Cat III boundary can be comfortable. However, much more research, of a transdisciplinary nature, is needed to better understand these issues.

\section{Acknowledgements}

The 4M consortium is funded by the Engineering and Physical Sciences Research Council (EPSRC) under their Sustainable Urban Environment programme (grant EP/F007604/1). It was a collaboration between the Universities of Loughborough, Newcastle, Sheffield, and De Montfort. The authors of this paper are grateful to Katherine Irvine who was instrumental in ensuring the Living in Leicester survey was successful. The map in Figure 1 is copyright the Ordnance Survey MasterMap and was provided through EDINA/DigiMap.

\section{References}

ANSI/ASHRAE (2010), Standard 55-2010 - Thermal Environmental Conditions for Human Occupancy (ANSI approved). American Society of Heating, Refrigerating and AirConditioning Engineers (ASHRAE), Atlanta, GA, USA. 
British Standards Institute (2008), Indoor Environmental Input Parameters for Design and Assessment of Energy Performance of Buildings Addressing Indoor Air Quality, Thermal Environment Lighting and Acoustics. British Standard BSEN15251, Brussels, BE.

CIBSE (2005), TM36 Climate Change and the Indoor Environment: Impacts and Adaptation. Chartered Institution of Building Services Engineers, London, UK.

CIBSE (2006), Guide A, Environmental Design, $7^{\text {th }}$ ed. Chartered Institution of Building Services Engineers, London, UK.

Cohen RR, Munro DK \& Ruysssvelt P (1993), Overheating Criteria for Non-air conditioned Buildings. Proceedings of CIBSE National Conference, UK, 1993.

de Dear RJ. A global database of thermal comfort experiments. ASHRAE Technical Data Bulletin 1998; 14: no 1: 15-26.

de Dear R \& Brager GS (2001), The adaptive model of thermal comfort and energy conservation in the built environment. International Journal of Biometrology, Vol. 45, No. 2, pp 100-108.

Eames M, Kershaw T \& Coley D (2011), On the creation of future probabilistic design weather years from UKCP09. Building Services Engineering Research and Technology, Vol. 32, No. 2, pp 127-142.

Eppel H \& Lomas KJ (1992), Comparison of alternative criteria for assessing overheating in buildings, BRE Support Contract Report 12. Leicester Polytechnic (De Montfort University), School of the Built Environment, Leicester, UK.

Field A (2005), Discovering Statistics Using SPSS, Second Edition. SAGE publications Ltd. London, p682-685.

Gauthier SM (2011) What are people's responses to thermal discomfort? Sensing clothing and activity levels using SenseCam, Proc. Conf. on Behaviour, Energy and Climate Change, The Berkeley Institute of the Environment, UC Berkeley, $30^{\text {th }}$ November 2011, 18pp, [Available at http://escholarship.org/uc/item/2ww9116s, accessed $17^{\text {th }}$ June 2012]

Hacker JN, De Saulles TP, Minson, AJ \& Holmes MJ (2008), Embodied and operational carbon dioxide emissions from housing: A case study on the effects of thermal mass and climate change. Energy and Buildings, Vol. 40, pp 375-384.

Hajat S, Kovats RS, Atkinson RW \& Haines A (2002), Impact of hot temperatures on death in London: a time series approach. Journal of Epidemiology and Community Health, Vol. 56, pp 367-372.

Hunt DRG \& Gidman MI (1982), A national field survey of house temperatures. Building and Environment, Vol. 17, No. 2, pp 107-124.

INNOVA (2002) Thermal Comfort, AirTech instruments, 25pp. [Available at, http://tinyurl.com/7fy4g3x, accessed 12 June 2012]

International Organization for Standardization (2005), ISO 7730: Ergonomics of the thermal environment - analytical determination and integration of thermal comfort using calculation of PMV and PPD indices and local thermal comfort criteria. International Organization for Standardization, Geneva, CH.

Kane T, Firth SK, Allinson D, Irvine KN \& Lomas KJ (2011), Understanding occupant heating practices in UK dwellings. Proceedings of the World Renewable Energy Congress, Linköping, Sweden, 8 - 11 May 2011.

Lomas KJ, Bell MC, Firth SK, Gaston KJ, Goodman P, Leake JR, Namdeo A, Rylatt M, Allinson D, Davies ZG, Edmondson JL, Galatioto F, Brake JA, Guo L, Fill G, Irvine KN, 
Taylor SC \& Tiwary A (2010), The carbon footprint of UK Cities: 4M: measurement, modelling, mapping and measurement. ISOCARP Review, Vol. 06, pp 168 - 191.

Lomas,KJ \& Giridharan,R, (2012) Thermal comfort standards, measured internal temperatures and thermal resilience to climate change of free-running buildings: a case-study of hospital wards, Building and Environment, 55, pp57-72.

Lomas KJ, Giridharan R, Short CA Short and Fair AJ (2012), Resilience of 'Nightingale' hospital wards in a changing climate, Building Serv. Eng. Res. Technol. Vol. 33, No. 1, pp. 81-103.

Novieto DT and Zhang Y (2010), Thermal comfort implications of the aging effect on metabolism, cardiac output and body weight, Proc. Conf. Adapting to Change: New Thinking on Comfort Cumberland Lodge, Windsor, UK, 9-11 April 2010. London: Network for Comfort and Energy Use in Buildings.

Mavrogianni A, Wilkinson P, Davies M, Biddulph P \& Oikonomou E (2012). Building characteristics as determinants of propensity to high indoor summer temperatures in London dwellings. Building and Environment, publication pending.

McCartney KJ, Nicol JF. Developing an Adaptive Control Algorithm for Europe: Results of the SCATs Project. Energy and Buildings 2002; 34(6): 623-35

Mayor of London (2008), The London Climate Change Adaptation Strategy, Draft Report. Greater London Authority, London, UK.

National Health Service (2011), Heatwave plan for England: Protecting health and reducing harm from extreme heat and heatwaves. National Health Service, London, UK.

Office for National Statistics (2010), Results of the 2001 Census. Office for National Statistics, Newport, Wales, UK.

Oreszczyn T, Hong SH, Ridley I \& Wilkinson P (2006), Determinants of winter indoor temperature in low income households in England. Energy and Buildings, Vol. 38, pp 245252.

Peacock AD, Jenkins DP \& Kane D (2010), Investigating the potential of overheating in UK dwellings as a consequence of extant climate change. Energy Policy, Vol. 38, pp 3277-3288. Peeters, L., Dear, R. d., Hensen, J., \& D'haeseleer, W. (2009), Thermal comfort in residential buildings: Comfort values and scales for building energy simulation. Applied Energy, 86, 772-780.

Shipworth M, Firth SK, Gentry, MI, Wright AJ, Shipworth DT \& Lomas KJ (2009), Central heating thermostat settings and timing: building demographics. Building Research and Information, Vol. 38, No. 1, pp 50-69.

Shove E, Chappels H, Lutzenhiser L and Hackett B (2008) Comfort in a lower carbon society, Editorial, Building Research and Information, Vol. 36, No. 4, p307-311.

Summerfield AJ, Lowe, RJ, Bruhns HR, Caeiro JA, Steadman JP \& Oreszczyn T (2007), Milton Keynes Energy Park revisited: Changes in internal temperatures and energy usage. Energy and Buildings, Vol. 39, pp 783-791.

Tempcon Instrumentation Ltd, 2010, http://www.tempcon.co.uk/index.html [Accessed 23rd December 2010]

World Health Organisation (2008), Improving public health response to extreme weather/heat-waves - EuroHEAT. Meeting report, Bonn, Germany, 22-23 March 2007. WHO Regional Office for Europe, Copenhagen, DM. 
Green Open Access Version

Wright AJ, Young AN \& Natarajan S (2005), Dwelling temperatures and comfort during the August 2003 heat wave. Building Services Engineering Research \& Technology, Vol. 26, No. 4, pp 285-300.

Yohanis YG \& Mondol JD (2010), Annual variation of temperature in a sample of UK dwellings. Applied Energy, Vol. 87, No. 2, pp 681-690. 
Lomas and Kane, Summertime temperatures, BR\&I, Tables

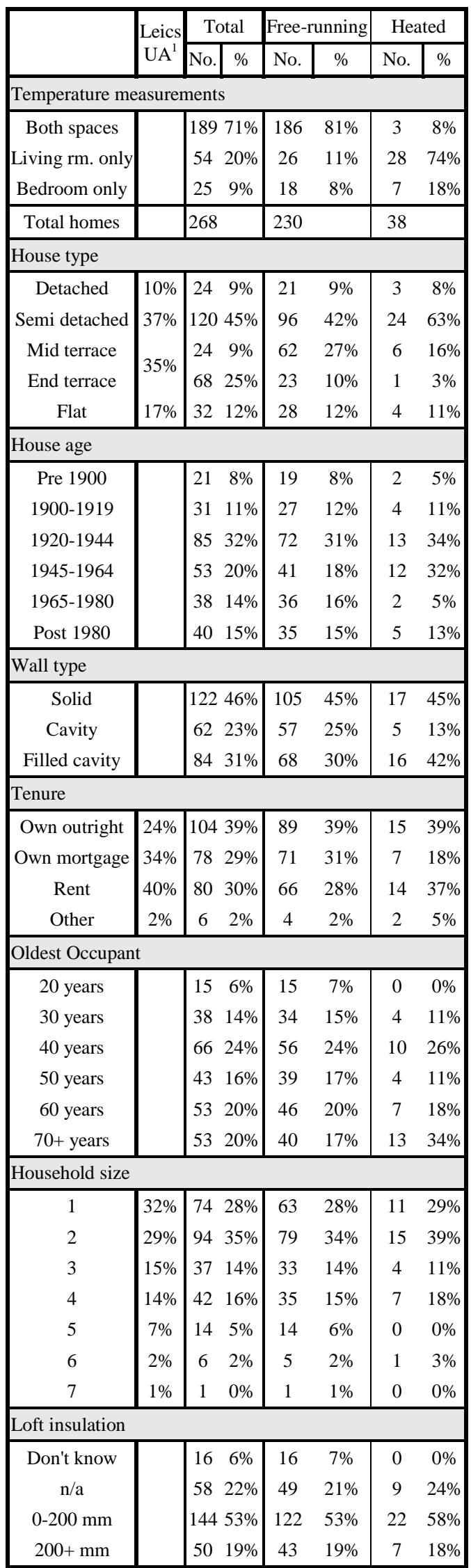

${ }^{1}$ Leicester Unitary Authority data, National Census of 2001(ONS, 2010)

Table 1. The samples of free-floating and heated homes 


\begin{tabular}{|c|c|c|c|c|c|c|c|}
\hline & \multirow[b]{2}{*}{$\begin{array}{l}\text { Number } \\
\text { (living, bed) }\end{array}$} & \multicolumn{2}{|c|}{ Living room (08:00-22:00) } & \multicolumn{2}{|c|}{ Living room (18:00-22:00) } & \multicolumn{2}{|c|}{ Bedroom (23:00-07:00) } \\
\hline & & $\begin{array}{c}\text { More than } 5 \% \\
\text { hours over } \\
25^{\circ} \mathrm{C} \\
\end{array}$ & $\begin{array}{c}\text { More than } 1 \% \\
\text { hours over } \\
28^{\circ} \mathrm{C} \\
\end{array}$ & $\begin{array}{c}\text { More than } 5 \% \\
\text { hours over } \\
25^{\circ} \mathrm{C} \\
\end{array}$ & $\begin{array}{c}\text { More than } 1 \% \\
\text { hours over } \\
28^{\circ} \mathrm{C} \\
\end{array}$ & $\begin{array}{c}\text { More than } 5 \% \\
\text { hours over } \\
24^{\circ} \mathrm{C} \\
\end{array}$ & $\begin{array}{c}\text { More than } 1 \% \\
\text { hours over } \\
26^{\circ} \mathrm{C} \\
\end{array}$ \\
\hline Detached & 18,21 & $9(50 \%)$ & 7 (39\%) & $10(56 \%)$ & $6(33 \%)$ & 19 (90\%) & 18 (86\%) \\
\hline Semi detached & 92,89 & $50(54 \%)$ & $22(24 \%)$ & 54 (59\%) & $24(26 \%)$ & 80 (90\%) & 79 (89\%) \\
\hline Mid terrace & 53,52 & 29 (55\%) & $11(21 \%)$ & $32(60 \%)$ & $12(23 \%)$ & $52(100 \%)^{*}$ & $46(88 \%)$ \\
\hline End terrace & 22,21 & $14(64 \%)$ & $5(23 \%)$ & $16(73 \%)$ & $9(41 \%)$ & 19 (90\%) & 20 (95\%) \\
\hline Flat & 27,21 & 20 (74\%)* & $13(48 \%)^{* *}$ & $21(78 \%)^{*}$ & $13(48 \%)^{* *}$ & 19 (90\%) & 17 (81\%) \\
\hline Total & 212, 204 & 122 & 58 & 133 & 51 & 189 & 180 \\
\hline \multicolumn{8}{|l|}{ House age } \\
\hline Pre 1900 & 15,16 & 7 (47\%) & $3(20 \%)$ & $7(47 \%)$ & $3(20 \%)$ & $14(86 \%)$ & 15 (94\%) \\
\hline 1900-1919 & 23,24 & $10(43 \%)$ & $4(17 \%)$ & $13(57 \%)$ & $4(17 \%)$ & $23(96 \%)$ & $21(88 \%)$ \\
\hline 1920-1944 & 69,65 & 36 (52\%) & $18(26 \%)$ & 39 (57\%) & $19(28 \%)$ & $62(95 \%)$ & 59 (91\%) \\
\hline 1945-1964 & 39, 35 & $28(72 \%)^{* *}$ & $13(33 \%)$ & 29 (74\%)* & $16(41 \%)$ & $32(91 \%)$ & 31 (89\%) \\
\hline $1965-1980$ & 35,33 & 24 (69\%) & $14(40 \%)^{*}$ & $26(74 \%)$ & $15(43 \%)^{*}$ & 31 (94\%) & 30 (91\%) \\
\hline Post 1980 & 31,31 & 17 (55\%) & $6(19 \%)$ & 19 (61\%) & 7 (23\%) & $26(84 \%)^{*}$ & $24(77 \%)^{* *}$ \\
\hline \multicolumn{8}{|l|}{ Wall type } \\
\hline Solid & 89, 88 & $43(48 \%)^{* *}$ & $17(19 \%)^{* *}$ & $46(52 \%)^{* *}$ & $20(22 \%)^{* *}$ & 83 (94\%) & 80 (91\%) \\
\hline Cavity & 54,49 & 35 (64\%) & 19 (35\%) & 39 (72\%)* & 20 (37\%) & 45 (92\%) & 45 (92\%) \\
\hline Filled cavity & 69,67 & $44(64 \%)$ & $22(32 \%)$ & 48 (70\%) & 24 (35\%) & 60 (90\%) & $55(82 \%)^{*}$ \\
\hline \multicolumn{8}{|l|}{ Tenure } \\
\hline Own outright & 80,85 & $48(60 \%)$ & $20(25 \%)$ & 51 (64\%) & 23 (29\%) & 79 (93\%) & 78 (92\%) \\
\hline Own mortgage & 65,62 & 34 (52\%) & $16(25 \%)$ & 39 (60\%) & 17 (26\%) & 58 (94\%) & $54(87 \%)$ \\
\hline Rent & 63,53 & 38 (60\%) & 22 (35\%) & 42 (67\%) & 23 (37\%) & 47 (89\%) & 44 (83\%) \\
\hline Other & 4,4 & $2(50 \%)$ & $0(0 \%)$ & $1(25 \%)$ & $1(25 \%)$ & $4(100 \%)$ & $4(100 \%)$ \\
\hline \multicolumn{8}{|c|}{ Oldest Occupant } \\
\hline 20 years & 14,10 & $6(43 \%)$ & $4(29 \%)$ & $7(50 \%)$ & $4(29 \%)$ & $10(100 \%)$ & $7(70 \%)^{*}$ \\
\hline 30 years & 31,31 & 17 (55\%) & 7 (23\%) & 19 (61\%) & $9(29 \%)$ & 28 (90\%) & $24(77 \%)^{* *}$ \\
\hline 40 years & 52,49 & 25 (48\%) & $14(27 \%)$ & 29 (56\%) & 17 (33\%) & 45 (92\%) & 46 (94\%) \\
\hline 50 years & 36,34 & $27(75 \%)^{* *}$ & $11(31 \%)$ & $28(78 \%)^{* *}$ & 12 (36\%) & 33 (97\%) & 33 (97\%) \\
\hline 60 years & 40,44 & 24 (60\%) & 14 (35\%) & 26 (65\%) & 12 (30\%) & 41 (93\%) & 39 (87\%) \\
\hline $70+$ years & 39, 36 & $23(59 \%)$ & 8 (21\%) & $24(62 \%)$ & $10(26 \%)$ & 31 (86\%) & 31 (79\%) \\
\hline \multicolumn{8}{|l|}{ Household size } \\
\hline $1 \& 2$ & 132,127 & 73 (55\%) & $32(24 \%)$ & $76(58 \%)^{* *}$ & $36(27 \%)$ & 118 (93\%) & 111 (87\%) \\
\hline $3 \& 4$ & 62,63 & 37 (60\%) & 19 (31\%) & 45 (73\%)* & 21 (34\%) & 57 (90\%) & 57 (90\%) \\
\hline $5+$ & 18,14 & $11(61 \%)$ & 7 (39\%) & $11(61 \%)$ & 7 (39\%) & 13 (93\%) & 12 (86\%) \\
\hline \multicolumn{8}{|l|}{ Loft insulation } \\
\hline Don't know & 16,16 & $9(56 \%)$ & 3 (19\%) & $10(63 \%)$ & $3(19 \%)$ & $16(100 \%)$ & $16(100 \%)$ \\
\hline $\mathrm{n} / \mathrm{a}$ & 45,35 & 29 (64\%) & $14(31 \%)$ & 31 (69\%) & 15 (33\%) & 33 (94\%) & 29 (83\%) \\
\hline Under 200 & 110,114 & $56(51 \%)^{* *}$ & 27 (25\%) & 65 (59\%) & 31 (28\%) & 105 (95\%) & 102 (89\%) \\
\hline Above 200 & 41,39 & 28 (68\%) & 14 (34\%) & 27 (66\%) & 15 (37\%) & 34 (87\%) & 33 (85\%) \\
\hline
\end{tabular}

Entries are number of rooms exceeding stated static criterion and this value as a percentage of all rooms for the particular socio-technical characteristic.

Significant results ${ }^{* *} \mathrm{p}<0.05,{ }^{*} \mathrm{p}<0.1$.

Table 2. Statistical analysis of free-running spaces using static overheating criteria. 
Green Open Access Version

\begin{tabular}{|c|c|c|c|c|c|c|c|}
\hline & \multirow[b]{2}{*}{$\begin{array}{l}\text { Number } \\
\text { (living, bed) }\end{array}$} & \multicolumn{2}{|c|}{ Living room (08:00-22:00) } & \multicolumn{2}{|c|}{ Living room (18:00-22:00) } & \multicolumn{2}{|c|}{ Bedroom (23:00-07:00) } \\
\hline & & $\begin{array}{c}\text { More than 5\% } \\
\text { hours below } \\
\text { Cat II }\end{array}$ & $\begin{array}{c}\text { More than 5\% } \\
\text { hours below } \\
\text { Cat III }\end{array}$ & $\begin{array}{c}\text { More than } 5 \% \\
\text { hours below } \\
\text { Cat II }\end{array}$ & $\begin{array}{c}\text { More than } 5 \% \\
\text { hours below } \\
\text { Cat III }\end{array}$ & $\begin{array}{c}\text { More than 5\% } \\
\text { hours below } \\
\text { Cat II }\end{array}$ & $\begin{array}{c}\text { More than } 5 \% \\
\text { hours below } \\
\text { Cat III } \\
\end{array}$ \\
\hline Detached & 18,21 & $16(89 \%)^{* *}$ & $10(56 \%)^{* *}$ & $14(78 \%)^{* *}$ & $7(39 \%)^{*}$ & $17(81 \%)$ & $13(62 \%)$ \\
\hline Semi detached & 92,89 & $62(67 \%)$ & $28(30 \%)$ & $53(58 \%)$ & $18(20 \%)$ & $66(74 \%)$ & 49 (55\%) \\
\hline Mid terrace & 53,52 & $31(58 \%)$ & 19 (36\%) & $29(55 \%)$ & $13(25 \%)$ & $36(69 \%)$ & $24(46 \%)$ \\
\hline End terrace & 22,21 & $14(64 \%)$ & $12(55 \%)^{* *}$ & $12(55 \%)$ & 7 (32\%) & $14(67 \%)$ & $9(43 \%)$ \\
\hline Flat & 27,21 & $13(48 \%)^{*}$ & $4(15 \%)^{* *}$ & $8(30 \%)^{* *}$ & $3(11 \%)$ & $11(52 \%)^{*}$ & $4(19 \%)^{* *}$ \\
\hline Total & 212,204 & 136 & 73 & 116 & 48 & 144 & 99 \\
\hline \multicolumn{8}{|l|}{ House age } \\
\hline Pre 1900 & 15,16 & $12(80 \%)$ & $8(53 \%)$ & $9(60 \%)$ & $6(40 \%)^{*}$ & $11(69 \%)$ & $7(44 \%)$ \\
\hline $1900-1919$ & 23,24 & $16(70 \%)$ & $14(61 \%)^{* *}$ & $15(65 \%)$ & $10(43 \%)^{* *}$ & $15(63 \%)$ & $12(50 \%)$ \\
\hline $1920-1944$ & 69,65 & 48 (70\%) & 22 (32\%) & $44(64 \%)^{*}$ & 13 (19\%) & $52(80 \%)^{* *}$ & 36 (55\%) \\
\hline $1945-1964$ & 39, 35 & 21 (54\%) & $9(23 \%)$ & $17(44 \%)$ & $8(21 \%)$ & $25(71 \%)$ & 20 (57\%) \\
\hline $1965-1980$ & 35,33 & $20(57 \%)$ & $8(23 \%)$ & $16(46 \%)$ & $3(1 \%)^{* *}$ & $21(64 \%)$ & $11(33 \%)^{*}$ \\
\hline Post 1980 & 31,31 & $19(61 \%)$ & $12(39 \%)$ & $15(48 \%)$ & $8(26 \%)$ & $20(65 \%)$ & $13(42 \%)$ \\
\hline \multicolumn{8}{|l|}{ Wall type } \\
\hline Solid & 89, 88 & $65(73 \%)^{* *}$ & $37(42 \%)^{*}$ & $58(65 \%)^{* *}$ & $26(29 \%)^{*}$ & 64 (73\%) & 46 (52\%) \\
\hline Cavity & 54,49 & 34 (63\%) & 17 (31\%) & 28 (52\%) & $9(17 \%)$ & 37 (76\%) & 28 (57\%) \\
\hline Filled cavity & 69,67 & $37(54 \%)^{* *}$ & $19(28 \%)$ & $30(43 \%)^{* *}$ & $13(19 \%)$ & 43 (64\%) & 25 (37\%) \\
\hline \multicolumn{8}{|l|}{ Tenure } \\
\hline Own outright & 80,85 & 52 (65\%) & 29 (36\%) & 47 (59\%) & $18(23 \%)$ & $60(71 \%)$ & 39 (46\%) \\
\hline $\begin{array}{c}\text { Own } \\
\text { mortgage }\end{array}$ & 65,62 & 41 (65\%) & 23 (35\%) & 35 (54\%) & $14(22 \%)$ & 45 (73\%) & 34 (55\%) \\
\hline Rent & 63,53 & 39 (62\%) & 19 (30\%) & 31 (49\%) & 15 (24\%) & 35 (66\%) & 22 (42\%) \\
\hline Other & 4,4 & $4(100 \%)$ & $2(50 \%)$ & 3 (75\%) & $1(25 \%)$ & $4(100 \%)$ & $4(100 \%)$ \\
\hline \multicolumn{8}{|l|}{ Oldest Occupant } \\
\hline 20 years & 14,10 & 8 (57\%) & $5(36 \%)$ & $8(57 \%)$ & $3(21 \%)$ & $7(70 \%)$ & $6(10 \%)$ \\
\hline 30 years & 31,31 & 20 (65\%) & 9 (29\%) & $16(52 \%)$ & $8(26 \%)$ & 20 (65\%) & 11 (35\%) \\
\hline 40 years & 52,49 & 36 (69\%) & $24(46 \%)^{*}$ & 33 (64\%) & 15 (29\%) & 38 (78\%) & 28 (57\%) \\
\hline 50 years & 36,34 & 21 (58\%) & $6(17 \%)^{* *}$ & $15(42 \%)^{*}$ & $3(1 \%)^{* *}$ & 21 (62\%) & $16(47 \%)$ \\
\hline 60 years & 40,44 & 21 (53\%)* & 14 (35\%) & $16(40 \%)^{* *}$ & $11(28 \%)$ & 28 (64\%) & $18(41 \%)$ \\
\hline $70+$ years & 39,36 & 30 (77\%)* & 15 (38\%) & $28(72 \%)^{* *}$ & $8(21 \%)$ & 30 (83\%) & 20 (56\%) \\
\hline \multicolumn{8}{|l|}{ Household size } \\
\hline $1 \& 2$ & 132,127 & $90(68 \%)^{*}$ & 48 (36\%) & 77 (58\%) & 34 (26\%) & $95(75 \%)^{*}$ & 65 (51\%) \\
\hline $3 \& 4$ & 62,63 & 35 (56\%) & $21(34 \%)$ & 30 (48\%) & $11(18 \%)$ & 41 (65\%) & $29(46 \%)$ \\
\hline $5+$ & 18,14 & $11(61 \%)$ & $4(22 \%)$ & $9(50 \%)$ & 3 (17\%) & 8 (57\%) & 5 (36\%) \\
\hline \multicolumn{8}{|l|}{ Loft insulation } \\
\hline Don't know & 16,16 & 12 (75\%) & 5 (31\%) & $11(69 \%)$ & $4(25 \%)$ & $14(88 \%)$ & $9(56 \%)$ \\
\hline $\mathrm{n} / \mathrm{a}$ & 45,35 & 26 (58\%) & 12 (27\%) & $20(44 \%)$ & $8(18 \%)$ & 23 (66\%) & $11(31 \%)^{* *}$ \\
\hline Under 200 & 110,114 & 71 (65\%) & $44(40 \%)^{*}$ & 60 (55\%) & 27 (25\%) & 81 (71\%) & 60 (53\%) \\
\hline Above 200 & 41, 39 & 27 (66\%) & 12 (29\%) & $25(61 \%)$ & $9(22 \%)$ & $26(67 \%)$ & $19(49 \%)$ \\
\hline
\end{tabular}

Entries are number of rooms exceeding stated adaptive model criterion and this value as a percentage of all rooms for the particular sociotechnical characteristic.

Significant results_ ${ }^{* *} \mathrm{p}<0.05,{ }^{*} \mathrm{p}<0.1$.

Table 3. Statistical analysis of free-running spaces using adaptive thermal comfort criteria of BSEN15251. 
Lomas and Kane, Summertime Temps, BR\&I, Figures

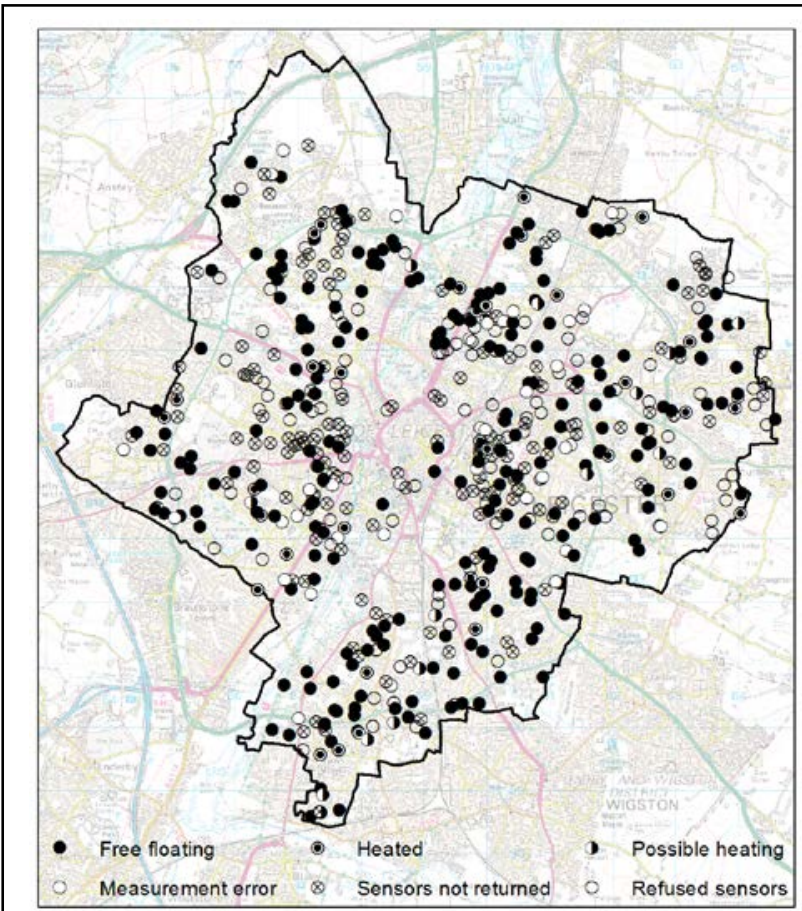

Figure 1: Leicester and the households surveyed: the 282 darker dots indicate those for which useable

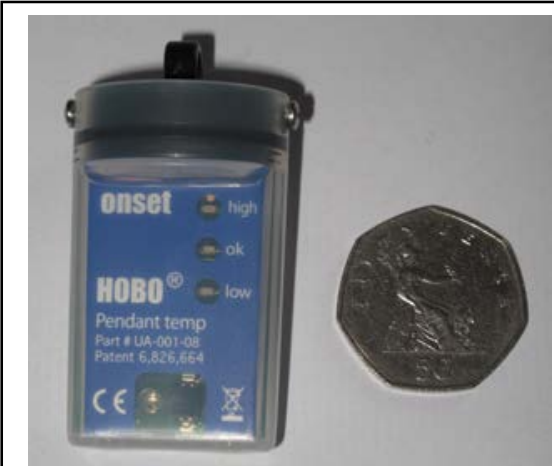

Figure 2: Hobo data logger used to measure indoor air temperature. 
Green Open Access Version

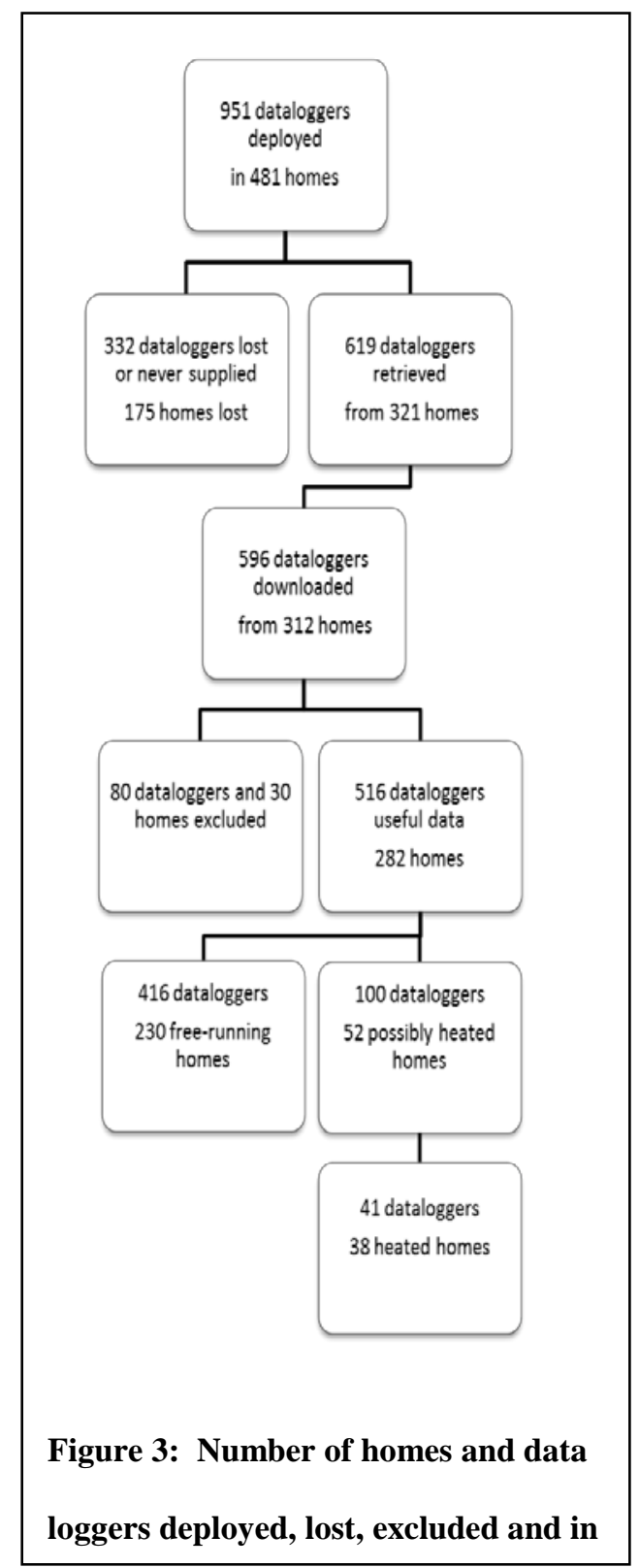


Green Open Access Version
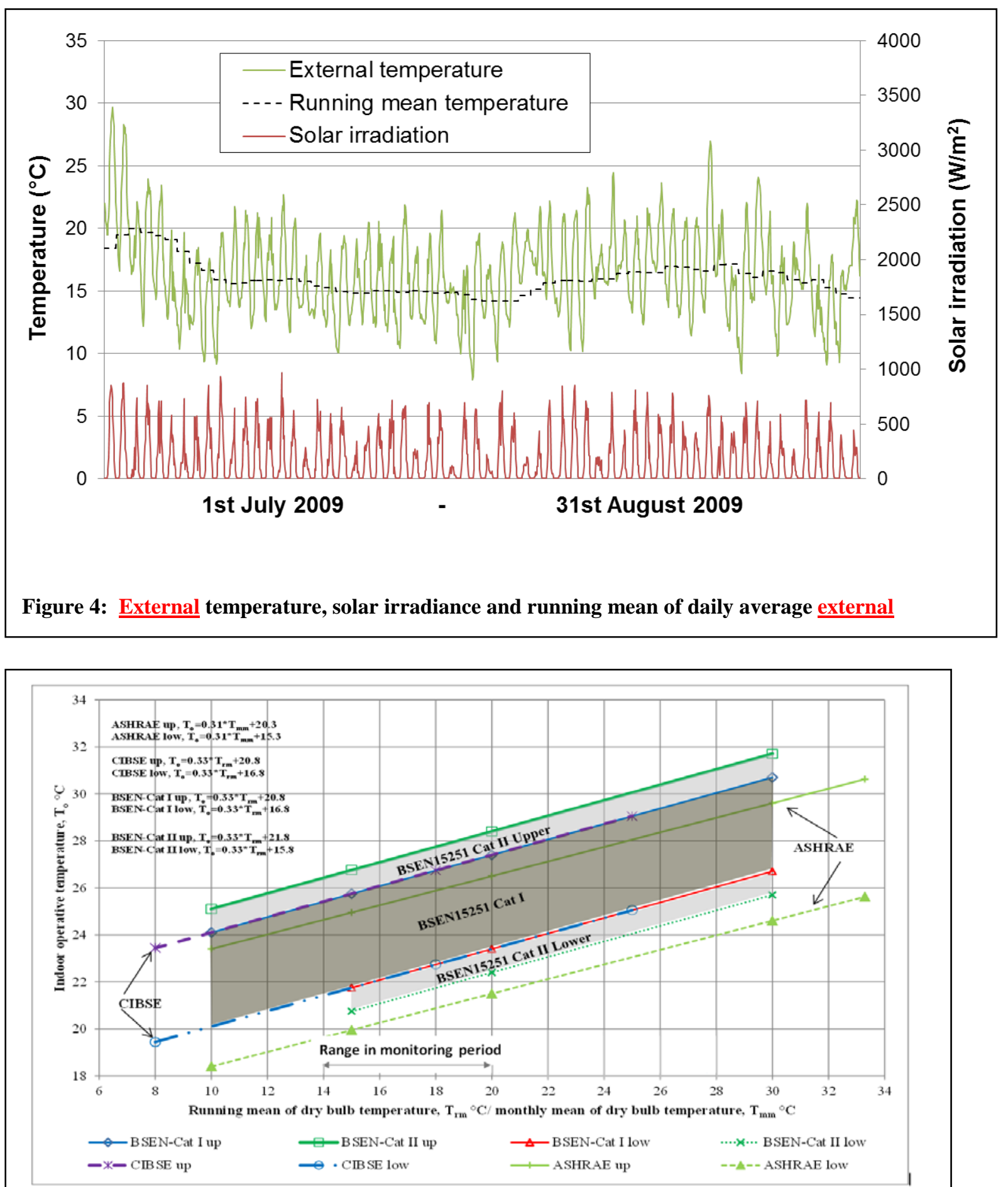

Figure 5: Comparison of adaptive thermal comfort standards (after Lomas and Giridharan, 2012) 

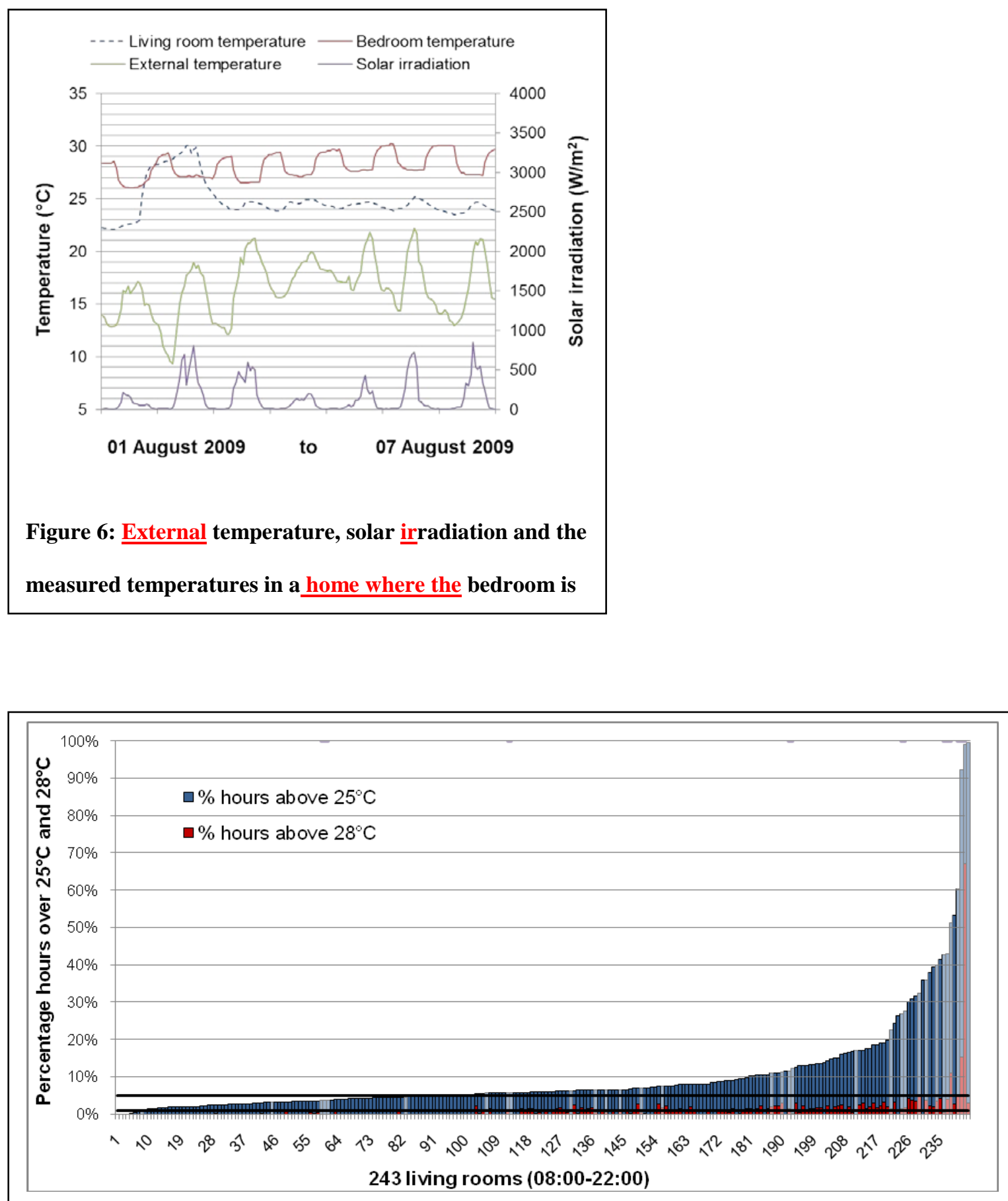

Figure 7: Percentage of hours with measured temperatures over $28^{\circ} \mathrm{C}$ and $25^{\circ} \mathrm{C}$ in all living rooms 

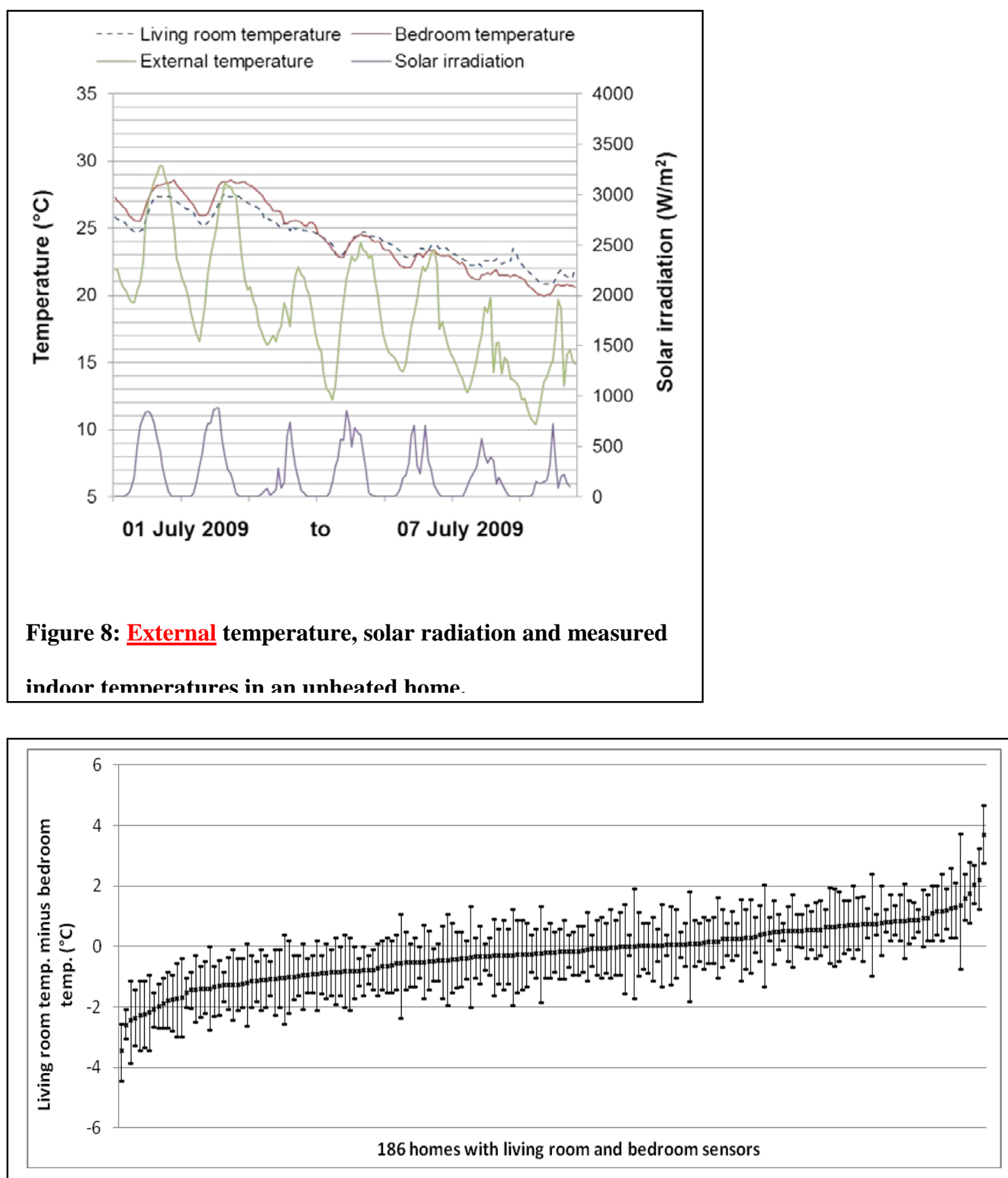

Figure 9: Difference between the mean measured living room and bedroom temberatures and 
Green Open Access Version
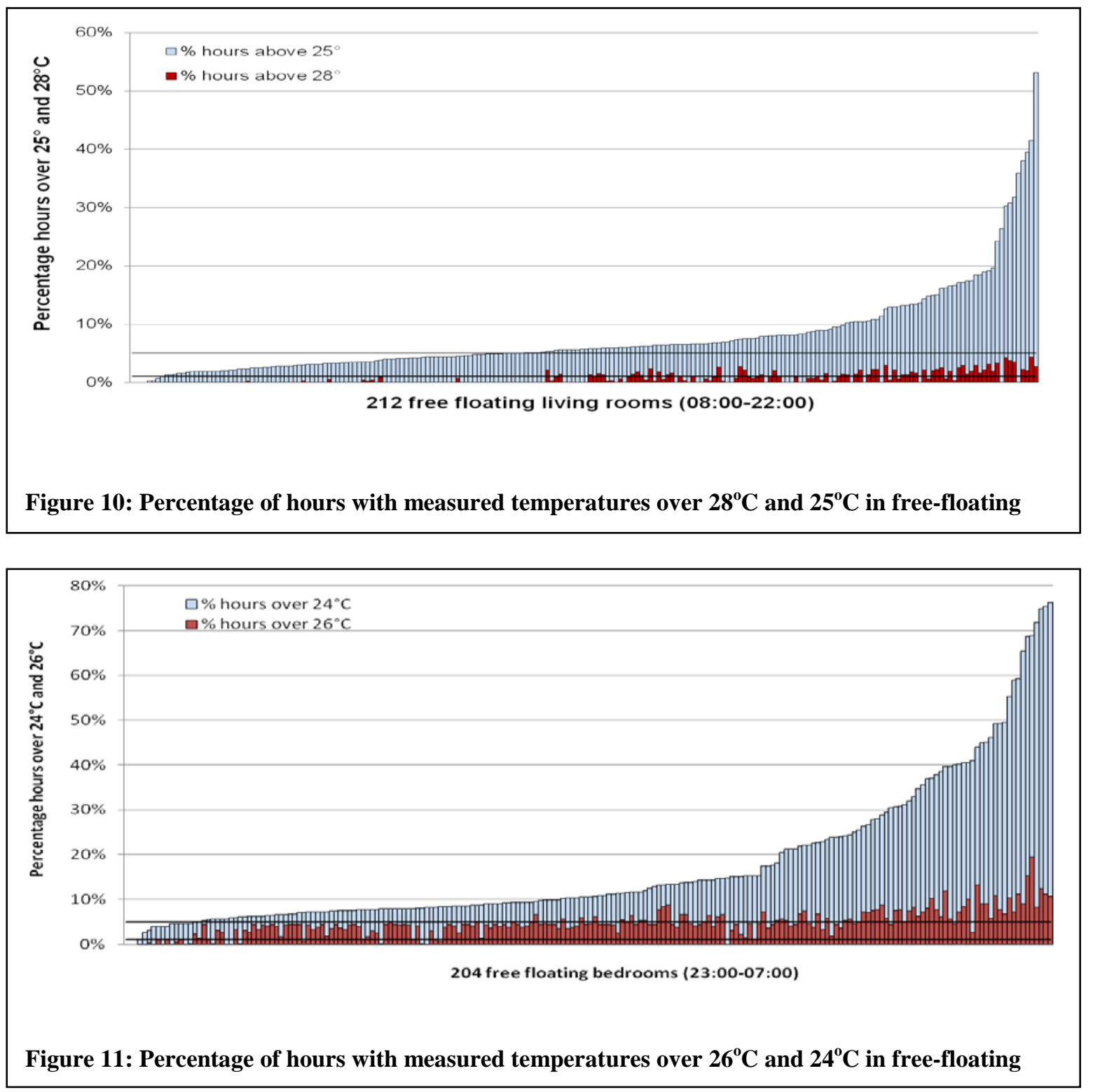


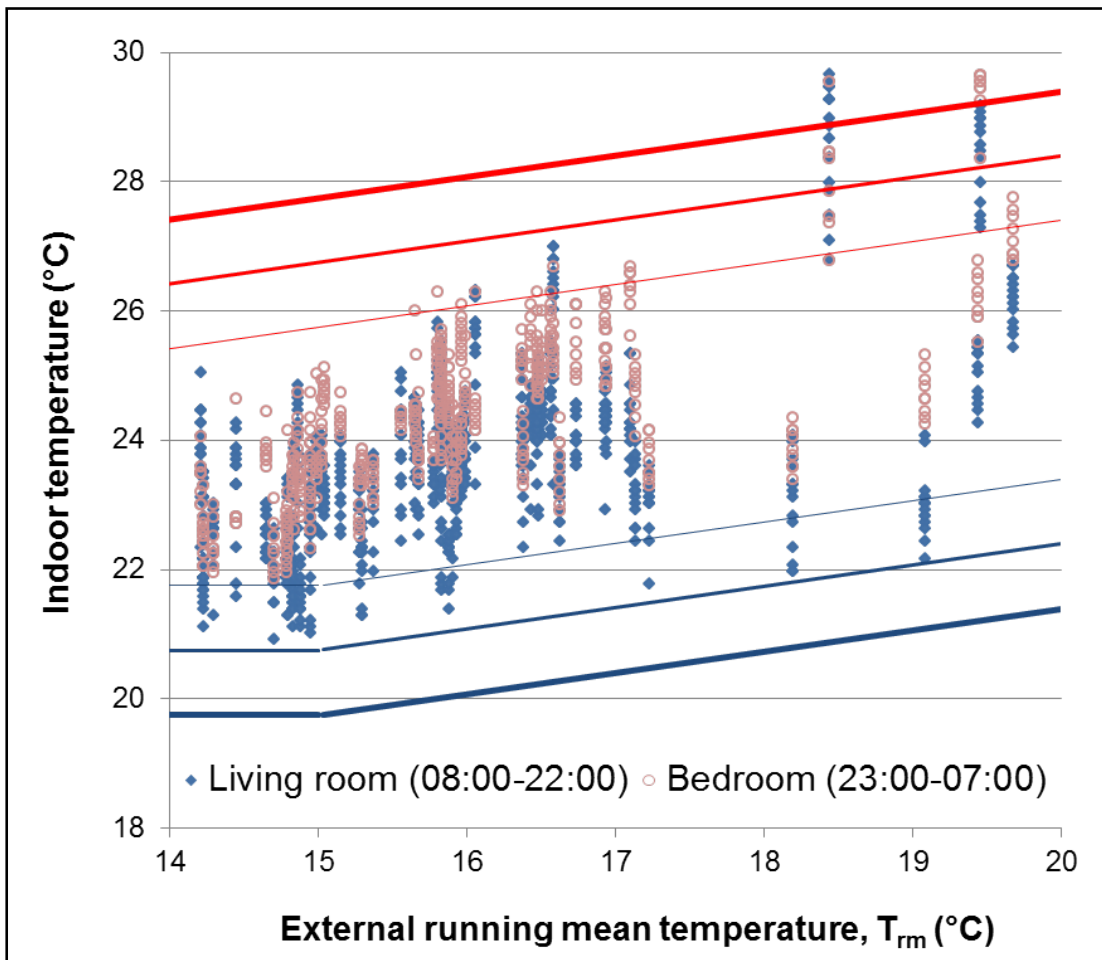

Figure 12: BSEN15251 thresholds and the hourly temperatures

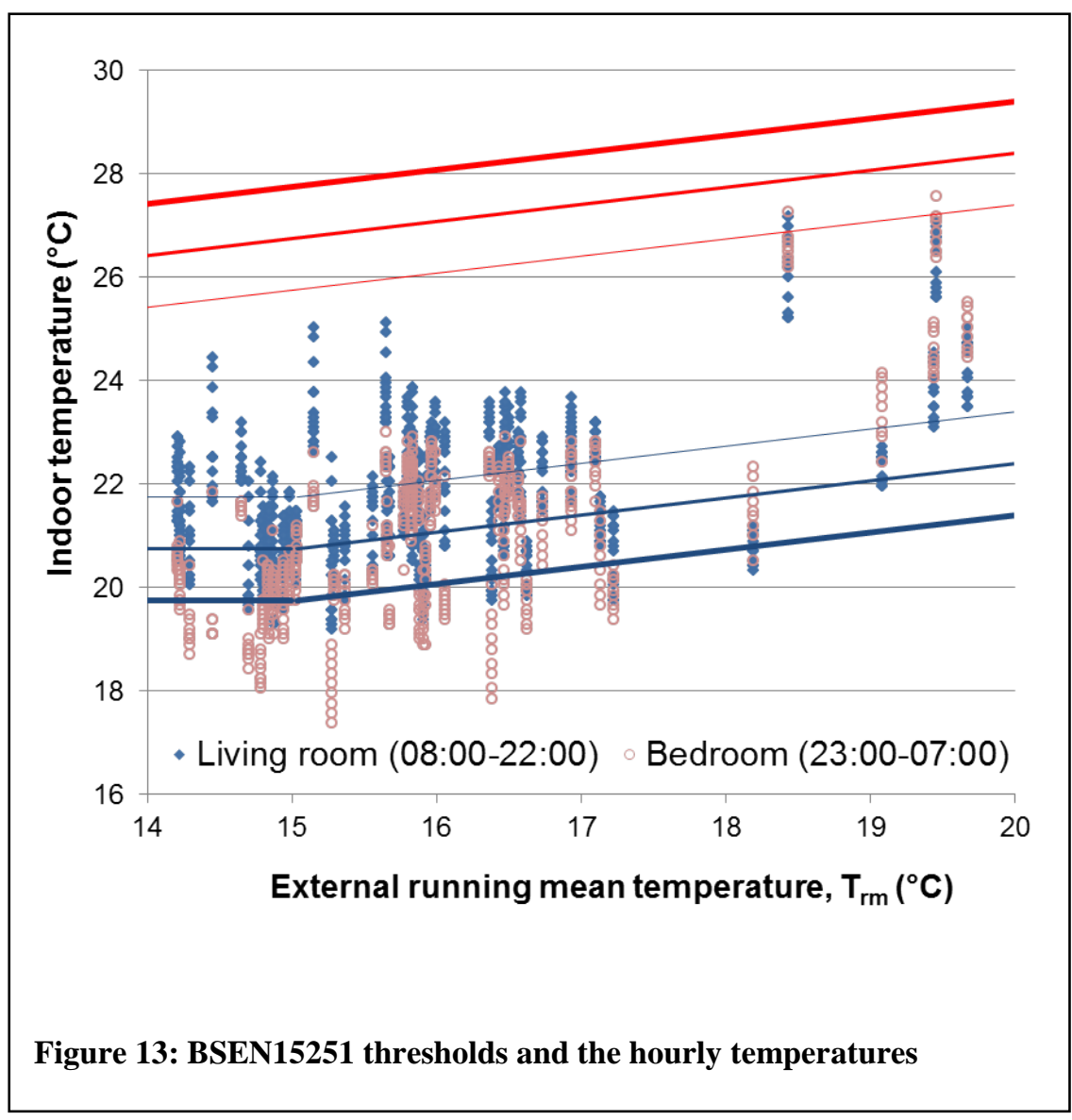




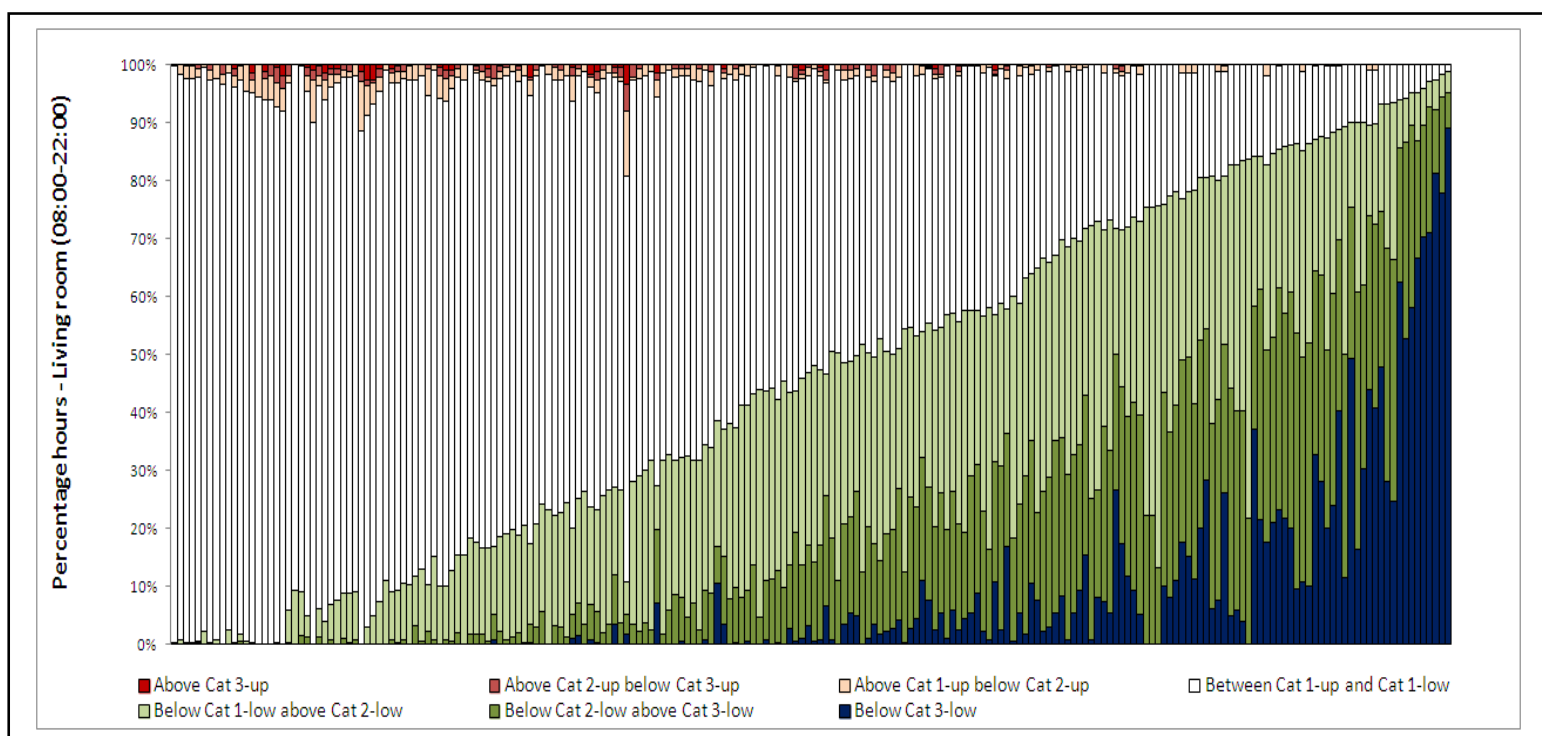

Figure 14: Percentage of hours when the measured hourly living room temperature is within each

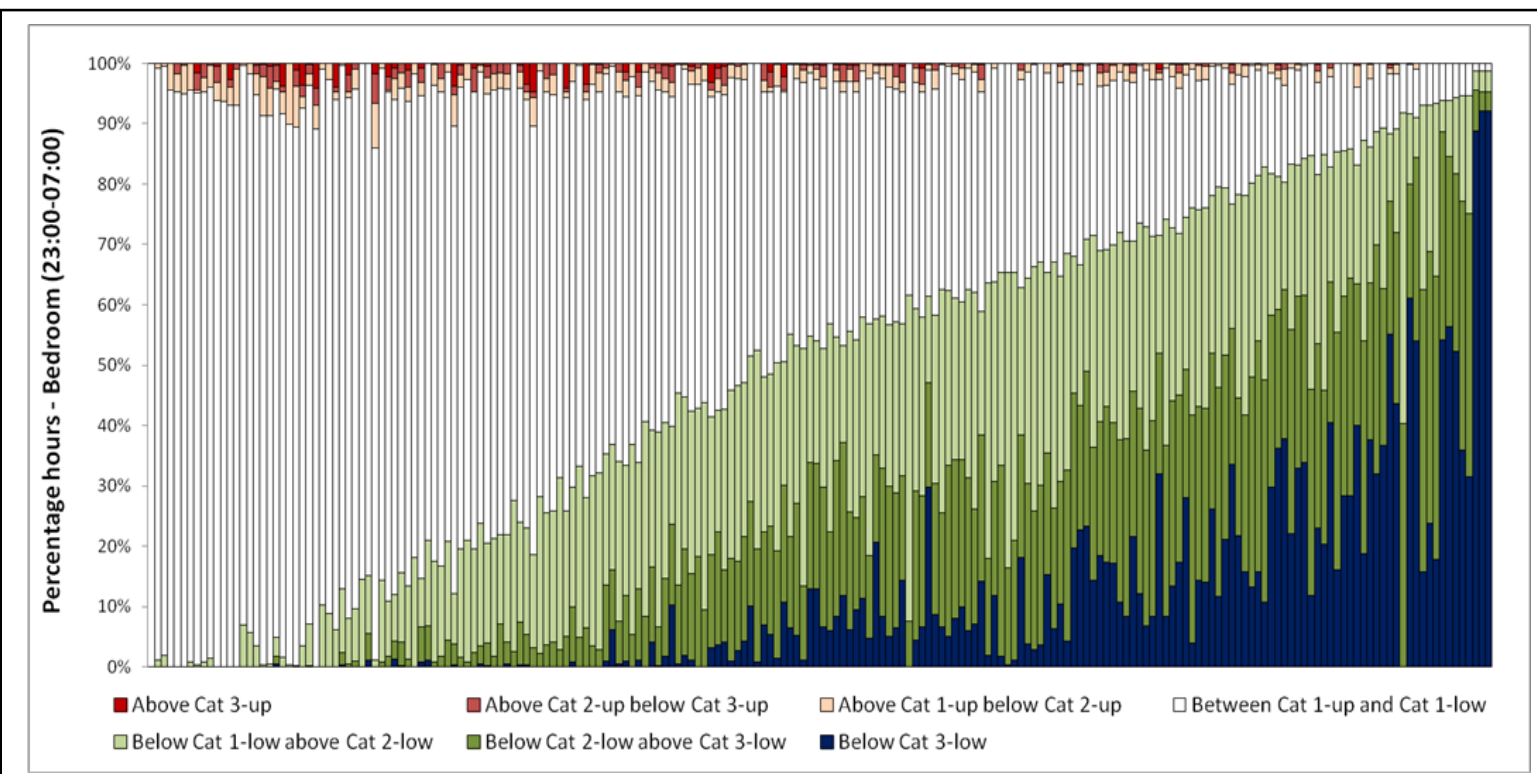

Figure 15: Percentage of hours when the measured hourly bedroom temperature is in each 